Suspended Sediment Flux in the San Francisco Estuary: Part IChanges in the Vertical Distribution of Suspended Sediment and Bias in Estuarine Sediment Flux Measurements

\author{
Livsey, DN
}

http://hdl.handle.net/10026.1/15970

10.1007/s12237-020-00734-z

Estuaries and Coasts

Springer Science and Business Media LLC

All content in PEARL is protected by copyright law. Author manuscripts are made available in accordance with publisher policies. Please cite only the published version using the details provided on the item record or document. In the absence of an open licence (e.g. Creative Commons), permissions for further reuse of content should be sought from the publisher or author. 


\title{
Suspended Sediment Flux in the San Francisco Estuary: Part I-Changes in the Vertical Distribution of Suspended Sediment and Bias in Estuarine Sediment Flux Measurements
}

\author{
D. N. Livsey ${ }^{1}$ • M. A. Downing-Kunz ${ }^{1}$ - D. H. Schoellhamer ${ }^{1}$ - A. J. Manning ${ }^{2,3,4,5}$
}

Received: 24 October 2019 / Revised: 13 March 2020 / Accepted: 18 March 2020

(C) This is a U.S. government work and not under copyright protection in the U.S.; foreign copyright protection may apply 2020

\begin{abstract}
In this study, we investigate how changes in the vertical distribution of suspended sediment affect continuous suspended sediment flux measurements at a location in the San Francisco Estuary. Current methods for measuring continuous suspended sediment flux estimates relate continuous estimates of suspended-sediment concentration (SSC) measured at-a-point $\left(\mathrm{SSC}_{p t}\right)$ to discrete cross-section measurements of depth-averaged, velocity-weighted SSC $\left(\mathrm{SSC}_{x s}\right)$. Regressions that compute $\mathrm{SSC}_{x s}$ from continuous estimates of $\mathrm{SSC}_{p t}$ require that the slope between $\mathrm{SSC}_{p t}$ and $\mathrm{SSC}_{x s}$, controlled by the vertical distribution of SSC, is fixed. However, in tidal systems with suspended cohesive sediment, factors that control the vertical SSC profile - vertical turbulent mixing and downward settling of suspended sediment mediated by flocculation of cohesive sediment—constantly vary through each tide and may exhibit systematic differences between flood and ebb tides (tidal asymmetries in water velocity or particle size). We account for changes in the vertical SSC profile on estimates of $\mathrm{SSC}_{x s}$ using time series of the Rouse number of the Rouse-Vanoni-Ippen equation combined with optical turbidity measurements, a surrogate for $\mathrm{SSC}_{p t}$, to predict $\mathrm{SSC}_{x s}$ from 2009 to 2011 and 2013. Time series of the Rouse number were estimated by fitting the Rouse-Vanoni-Ippen equation to SSC estimated from optical-turbidity measurements taken at two elevations in the water column. When accounting for changes in the vertical SSC profile, changes in not only the magnitude but also the direction of cumulative sediment-flux measurements were observed. For example, at a mid-depth sensor, sediment flux estimates changed from $-319 \mathrm{kt}$ ( $\pm 65 \mathrm{kt}$, negative indicating net seaward transport) to $482 \mathrm{kt}$ ( $\pm 140 \mathrm{kt}$, positive indicating net landward transport) for 2009-2011 and from - $388 \mathrm{kt}$ ( $\pm 140 \mathrm{kt})$ to $1869 \mathrm{kt}$ ( $\pm 406 \mathrm{kt}$ ) for 2013-2016. At the study location, estimation of $\mathrm{SSC}_{x s}$ solely from $\mathrm{SSC}_{p t}$ resulted in sediment flux values that were underestimates on flood tides and overestimates on ebb tides. This asymmetry is driven by covariance between water velocity and particle settling velocity $\left(W_{s}\right)$ with larger $W_{s}$ on flood compared to ebb tides. Results of this study indicate that suspendedsediment-flux measurements estimated from point estimates of SSC may be biased if systematic changes in the vertical distribution of SSC are unaccounted for.
\end{abstract}

Communicated by Neil Kamal Ganju

Electronic supplementary material The online version of this article (https://doi.org/10.1007/s12237-020-00734-z) contains supplementary material, which is available to authorized users.

D. N. Livsey

dlivsey@usgs.gov

M. A. Downing-Kunz

mdowning-kunz@usgs.gov

D. H. Schoellhamer

dschoell@usgs.gov

A. J. Manning

andymanning@yahoo.com
1 United States Geological Survey, California Water Science Center, 6000 J Street, Placer Hall, Sacramento, CA 95819-6129, USA

2 HR Wallingford Ltd, Coasts \& Oceans Group, Wallingford OX10 8BA, UK

3 Energy \& Environment Institute, University of Hull, Hull HU6 7RX, UK

4 Department of Civil and Environmental Engineering, Stanford University, Stanford, CA 94305, USA

5 School of Biological and Marine Sciences, University of Plymouth, Plymouth PL4 8AA, UK 
Keywords Estuarine processes $\cdot$ Suspended sediment $\cdot$ Sediment flux $\cdot$ Sediment supply $\cdot$ Cohesive sediment $\cdot$ Flocculation $\cdot$ San Francisco estuary

\section{Introduction}

Accurate suspended sediment flux measurements in coastal settings are of increasing interest given the importance of sediment supply to coastal resiliency as sea level rises and the influence of suspended sediment on coastal water quality. However, current approaches to measure suspended sediment flux in tidal systems often exhibit very large uncertainty in flux magnitude and at times net direction (e.g., Shellenbarger et al. 2013). Accurately measuring suspended sediment flux in tidally affected coastal systems is especially difficult because the total flux is the sum of two very large numbers that are often an order magnitude greater than the residual flux; thus, unaccounted-for biases in concentration estimates needed to compute fluxes may affect not only total flux magnitude but also sign (i.e., net seaward or net landward transport).

Typical methods for measuring suspended sediment flux use continuous point estimates of suspended sediment concentration (SSC) related to discrete cross-section averaged measurements of SSC $\left(\mathrm{SSC}_{x S}\right)$, paired with acoustic measurement of velocity to compute discharge and sediment flux (Ruhl and Simpson 2005; Levesque and Oberg 2012; Shellenbarger et al. 2013). The largest source of uncertainty in suspended sediment flux measurements is from scatter in the regression between continuous point estimates of SSC $\left(\mathrm{SSC}_{p t}\right)$ and discrete cross-section measurements of SSC $\left(\mathrm{SSC}_{x s}\right)$. Computation of suspended sediment flux using $\mathrm{SSC}_{x s}$ estimated from $\mathrm{SSC}_{p t}$ requires that the slope of $\mathrm{SSC}_{x s}\left(\mathrm{SSC}_{p t}\right)$, controlled by the vertical distribution of $\mathrm{SSC}$, is fixed. However, in tidal systems factors that control the vertical distribution of SSC, vertical turbulent mixing and downward settling of suspended sediment mediated by flocculation of cohesive sediment are constantly changing and may exhibit systematic differences between flood and ebb tides (e.g., tidal asymmetries in water velocity or particle size). Thus, unaccounted-for-systematic differences in the vertical SSC concentration profile may result in biased suspended sediment flux estimates.

In this study, we investigate how changes in the vertical SSC profile affect suspended sediment flux measurements in the San Francisco Estuary (SFE), the second largest estuary on the west coast of the USA using data collected from 2009 to 2011 by Shellenbarger et al. (2013) and 2013-2016 and 2018 (this study). The primary objectives of this work are to (1) ascertain the impact of not accounting for systemic changes in the vertical distribution of SSC on current methods for measuring sediment flux in tidal systems (detailed in part I) and (2) investigate the impact of the recent, record-breaking 2013-2016 California drought on sediment fluxes in Lower South Bay, an embayment of the SFE (detailed in part II).

In part I, we demonstrate that when changes in the vertical distribution of suspended sediment are unaccounted for, sediment flux estimates in tidal systems may be strongly biased. The vertical SSC profile was described using the Rouse number of the Rouse-Vanoni-Ippen equation (García 2008) fit to SSC estimated from optical-turbidity measurements taken at two elevations in the water column. Time series of optical turbidity, a surrogate for $\mathrm{SSC}_{p t}$, and Rouse number were utilized to predict time series of $\mathrm{SSC}_{x s}$ and compute continuous estimates of suspended sediment flux from 2009 to 2011 and 2013-2016. Time series of measured water velocity and estimated settling velocity derived from the Rouse-Vanoni-Ippen and sediment-transport equations are utilized to investigate the influence of vertical turbulent mixing and flocculation on SSC profiles. Rouse number time series were validated by 43 cross-channel transects of acoustic Doppler current profile (ADCP) acoustic backscatter data converted to SSC and 199 vertical profiles of SSC collected from 2008 to 2018. Settling velocity time series are validated by in situ measurements of floc settling velocity.

In the SFE, tidal velocity ranges from 0 to $1 \mathrm{~m} / \mathrm{s}$ while the settling velocity of suspended silts and clays ranges from $<1$ to $20 \mathrm{~mm} / \mathrm{s}$ (Manning and Schoellhamer 2013). Past studies of suspended sediment revealed that aggregate (as opposed to primary) particle size is $40 \%$ larger on flood tide than on ebb tide (Gartner et al. 2001) and that changes in the predominantly mud-sized particles of the suspended sediment arise from disaggregation of macroflocs and flocculation of microflocs (Manning and Dyer 2007; Soulsby et al. 2013; Manning and Schoellhamer 2013; Manning et al. 2017). Because similar tidal oscillations in water velocity and flocculation have been documented in estuaries worldwide (Eisma 1986; Manning 2004a; Mikeš and Manning 2010; Markussen and Anderson, 2013, 2014; Sahin et al. 2017a, 2017 b), results of this work may be applicable to many tidal system transporting cohesive sediment.

\section{Study Area}

San Francisco Estuary comprises two prominent subestuaries that are hydrologically distinct: North Bay, consisting of Suisun Bay, San Pablo Bay, and Central Bay, a classic estuary with freshwater inflow from a watershed draining $40 \%$ of California's land area, and South Bay, a tidal lagoon with little freshwater inflow (Fig. 1). San Francisco Estuary is 
Fig. 1 San Francisco Estuary with major tributaries and locations of referenced sensors

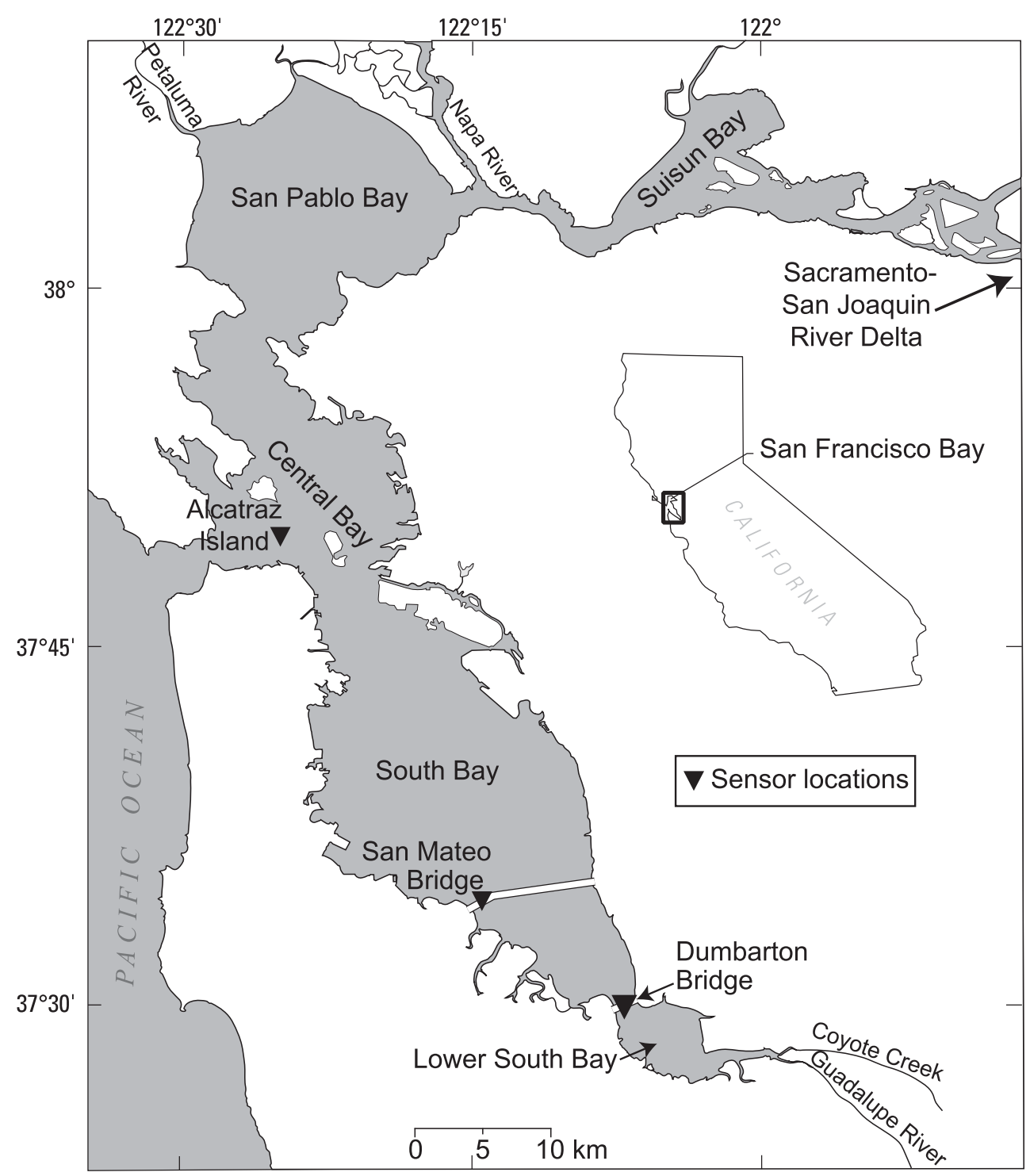

characterized by a natural channel-shoal bathymetry with a narrow, deep $(\sim 10-20 \mathrm{~m})$ tidal channel bounded by broad, shallow mudflats (Conomos et al. 1985). North Bay extends upstream to the confluence of the Sacramento and San Joaquin Rivers (Delta), which provide $93 \%$ of the freshwater inflow into San Francisco Estuary (McKee et al. 2013). Local tributaries located along the margin of San Francisco Estuary contribute the remaining $7 \%$ of freshwater inflow but contribute approximately $61 \%$ of suspended sediment to the bay (McKee et al. 2013). Of these local tributaries, Napa River, Alameda Creek, and Guadalupe River have the highest freshwater runoff (Webster et al. 2005). The Mediterranean climate is characterized by wet cool winters and warm dry summers. Most of the precipitation over the bay and freshwater inflow occurs from October to April (Conomos et al. 1985).

Lower South Bay (LSB) is the southernmost subembayment of South Bay, bounded to the north (seaward) by the Dumbarton Narrows (spanned by
Dumbarton Bridge) and to the south (landward) by Coyote Creek and Guadalupe River, the largest tributaries of the subembayment (Fig. 1). At mean tide level, LSB mean water depth and surface area are $2.6 \mathrm{~m}$ and $34 \mathrm{~km}^{2}$, respectively (Hager and Schemel 1996). Maximum water depth is $20 \mathrm{~m}$, and the mixed semidiurnal tidal range is approximately $3 \mathrm{~m}$ (Shellenbarger et al. 2013). Maximum depthaveraged tidal velocity in Dumbarton Narrows reaches $1 \mathrm{~m} / \mathrm{s}$ (Shellenbarger et al. 2013). LSB and Dumbarton Narrows are not routinely dredged (Barnard et al. 2013), and no dredging in Dumbarton Narrows was noted over the study period. The channel bed $\sim 5 \mathrm{~km}$ north and south of Dumbarton Bridge is composed of clay and fine silt exhibiting a mean grain size ranging from 6 to $16 \mu \mathrm{m}$ (McGann et al. 2013). During summer months, effluent from wastewater treatment facilities adjacent to LSB often contributes more freshwater than LSB tributaries (Shellenbarger et al. 2013). 
Flocculation in the San Francisco Estuary varies longitudinally due to gradients in physical, chemical, and biologic processes (Manning and Schoellhamer 2013). From a near-bed, (i.e., $0.7 \mathrm{~m}$ above the bed) longitudinal transect beginning at the end of ebb tide and through the flood tide of the San Francisco Estuary, Manning and Schoellhamer (2013) found that salinity had little control on flocculation processes while turbulence-induced particle collisions had the largest control with longitudinal gradients in percent sand and biologic processes exhibiting secondary controls. Median settling velocity observed during the transect was $5.3 \mathrm{~mm} / \mathrm{s}$ with an interquartile range of $2.5-$ $6.4 \mathrm{~mm} / \mathrm{s}$. Suspended sediment in the San Francisco Estuary is predominantly composed of silt and clay; the sand fraction is greater in Central Bay and increases with landward distance in North Bay (Manning and Schoellhamer 2013). Large low-density fast-settling benthic macroflocs (e.g., Manning et al. 2011; Zhang et al. 2018), typically formed through flocculation (often referred to as aggregation) of much smaller-sized higherdensity aggregates known as microflocs (e.g., Eisma 1986; Manning 2004b, Manning et al., 2013), dominate suspended sediment particle mass in South Bay, while microflocs tend to dominate the suspended sediment particle mass in more marine locations of Central Bay and San Pablo Bay (Manning and Schoellhamer 2013; Manning et al. 2010).

\section{Methods}

\section{Suspended Sediment Flux Measurements}

All sampling for the measurement of suspended sediment flux at Dumbarton Bridge followed the index-velocity method (Ruhl and Simpson 2005; Levesque and Oberg 2012) and the EqualDischarge Increment method (Edwards and Glysson 1999), wherein continuous estimates of suspended-sediment flux are computed from regressions between continuous point measurements and discrete, cross-section averaged measurements of SSC and water velocity. Moored optical turbidity sensors (sonde 6920, probe 6136, YSI, Inc., Yellow Springs, OH, USA; any use of trade, firm, or product names is for descriptive purposes only and does not imply endorsement by the U.S. Government) were used to continuously measure turbidity, a surrogate for SSC. An acoustic Doppler current profiler (ADCP, Nortek Aquadopp $1 \mathrm{MHz}$, NortekUSA, Boston, MA, USA) was utilized to continuously measure water velocity and stage (Fig. 2). Continuous measurements with a 15-min sampling interval were then related to cross-section averaged measurements of water velocity and depth-averaged, velocity-weighted $\mathrm{SSC}\left(\mathrm{SSC}_{x s}\right)$. Cross-section water velocity was measured using a boatmounted ADCP (SonTek M9, Xylem, San Diego, CA, USA). All measurements of $\mathrm{SSC}_{x s}$ were collected using a US D-96 sampler (Edwards and Glysson 1999).

Turbidity sensors were positioned at two locations in the water column for the entire deployment from 2009 to 2011
Fig. 2 Schematic of sediment flux monitoring deployment at Dumbarton Bridge. The longterm monitoring deployment was used for the WY 2009-2011, WY 2013-2016, and April 2018 data collection efforts. The long-term monitoring deployment (black infilled symbols) consists of all instrumentation except the upper and lower optical sensors. The upper and lower optical sensors (white infilled symbols) were deployed from April 16, 2018 to April 18, 2018. In situ floc-cam measurements were collected on April 17, 2018 at the mid-depth optical sensor

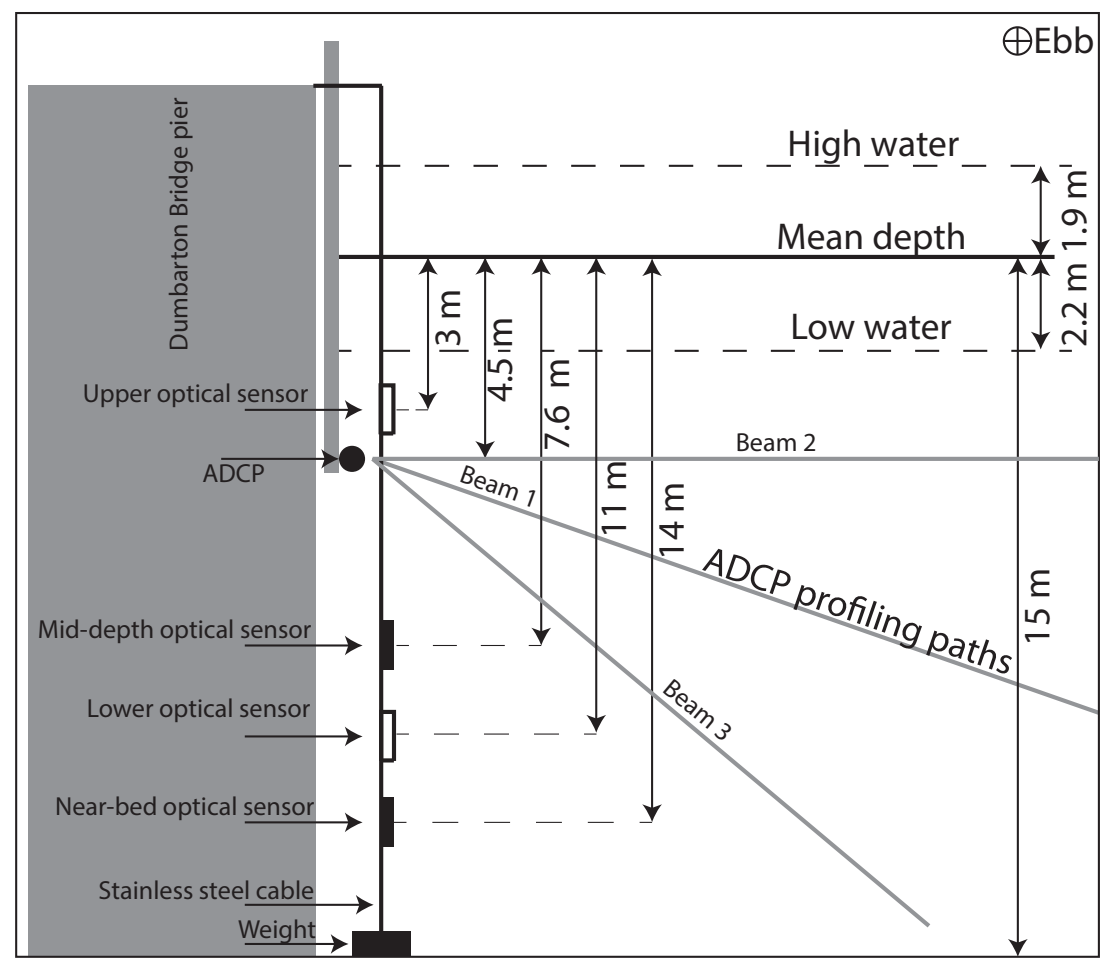


and 2013-2018: at mid depth (7.6 $\mathrm{m}$ above the bed at $0.5 \times H$, where $H$ is mean water depth) and near bed ( $1.2 \mathrm{~m}$ above the bed at $0.1 \times H$ ). During a 3-day sampling campaign in April 2018, two additional turbidity sensors were deployed at two other locations in the water column: upper $(12 \mathrm{~m}$ above the bed at $0.8 \times H$ ) and lower $(4 \mathrm{~m}$ above the bed at $0.3 \times H$; Fig. 2 ). The optical turbidity measurements were computed from the average of 24 measurements sampled over a 12-s duration. For the long-term deployment, sensors recorded data every 15 min. For the April 2018 sampling campaign, all sensors collected data every $30 \mathrm{~s}$. SSC bottle samples were collected at neither the lower sensor ( $4 \mathrm{~m}$ above the bed) nor the upper sensor (12 $\mathrm{m}$ above the bed). Regression parameters at the lower and upper sensors were estimated from linearly interpolating the slope and intercept with elevation from the mid-depth and near-bed sensor turbidity-toSSC regressions. The interpolation with elevation was based on the rationale that larger, faster-settling particles are expected closer to the bed and that larger particles increase the turbidity-to-SSC regression slope with depth (see Downing 2006, and references therein).

As noted by Shellenbarger et al. (2013), cross-section measurements were limited by shallow intertidal mudflats. See Shellenbarger et al. (2013) for cross-section measurement locations. The non-measured area of the cross section ranges from $<5 \%$ at mean lower low water to $20 \%$ at mean higher high water. A 3D tidal model with data from Elias et al. (2013) and without wind forcing indicates that cross-section measurements capture $98 \%$ of the total flow, with $2 \%$ of the total flow over the unmeasured shoals. Sediment-flux measurements on intertidal mud flats north of Dumbarton Bridge (Brand et al. 2010) from February to March 2009 indicated that prevailing northerly winds drive net sediment flux landward. SSC on the shoals ranged from 10 up to $120 \mathrm{mg} / \mathrm{l}$ similar to the $0.05-0.95$ quantile range of $\mathrm{SSC}_{x s}, 22$ to $99 \mathrm{mg} / \mathrm{l}$, observed at Dumbarton Bridge over the same period (Shellenbarger et al. 2013). If one assumes that SSC on the shoals is two to three times the measured $\mathrm{SSC}_{x s}$, a conservative upper limit, the unmeasured sediment flux would represent no more than $4-6 \%$ of the total cross-section flux. Given that SSC on the shoals is larger but of the same order of magnitude as $\mathrm{SSC}_{x s}$, the cross-section measurements that capture $98 \%$ of the total cross-sectional flow are expected to be representative of the net sediment flux for the entire cross section.

The index method utilizes regressions between the moored continuous "index" measurements of turbidity $\left(T_{b}\right)$, floodpositive velocity $\left(U_{i}\right)$, and stage $(p)$ to $\mathrm{SSC}_{x s}$; cross-sectional average water velocity $\left(U_{x s}\right)$; and cross-sectional area $\left(A_{x s}\right)$, respectively, to develop continuous time series of discharge $\left(Q_{x s}\right)$ and suspended sediment flux $\left(Q_{s}\right)$ with $\operatorname{SSC}_{x s}\left(T_{b}\right)$, $U_{x s}\left(U_{i}\right), A_{x s}(p)$, and the following:

$Q_{x s}=U_{x s} A_{x s}$
$Q_{s}=Q_{x s} \mathrm{SSC}_{x s}$

All directional quantities are defined as positive when in the flood-tide direction. The optimum regression equation forms for $\operatorname{SSC}_{x s}\left(T_{b}\right), U_{x s}\left(U_{i}\right)$, and $A_{x s}(p)$ were selected using the regression diagnostics of Helsel and Hirsch (2002) with regression data transformed as needed to reduce heteroscedasticity. We considered log transformations of $x$ and $y$ (i.e., $y(\log (x)), \log (y)(x)$, or $\log (y)(\log (x))$. Cumulative sediment flux $\left(\sum Q_{s}\right)$ was computed using untransformed and transformed regression data to ensure $\sum Q_{s}$ magnitude and direction did not change with model transformations. The transformation that minimized residual heteroscedasticity was used for final computation of $\sum Q_{s}$. Annual fluxes are presented by water year (WY, i.e., October 1 to September 30) since the onset of wet-season conditions occur in the month of October.

\section{The Effect of Changes in the Vertical Distribution of SSC on Suspended Sediment Flux Measurements}

Our hypothesis is that changes in the vertical distribution of $\mathrm{SSC}$ when unaccounted for in $\mathrm{SSC}_{p t}$-to-SSC $\mathrm{S}_{x s}$ regressions may result in biased suspended-sediment flux estimates. During periods of low water velocity and/or high particle settling, velocity suspended sediment will be concentrated closer to the bed, while during periods of increased water velocity and/or low particle settling, velocity suspended sediment will be more evenly distributed within the water column. In tidal systems with suspended cohesive sediment, water velocity and particle settling velocity may covary (e.g., Winterwerp 2002, Manning and Schoehllhamer, 2013; Sahin et al. 2017a); thus, the slope of a $\mathrm{SSC}_{p t}$-to-SSC${ }_{x s}$ regression may vary throughout the tide. This simple case omits the effect of stratification on vertical turbulent mixing, which would also impact the vertical distribution of suspended sediment.

To demonstrate how changes in the vertical distribution of SSC may affect $\mathrm{SSC}_{p t}$ estimates of $\mathrm{SSC}_{x s}$, we compute theoretical $\mathrm{SSC}_{p t}\left(\mathrm{SSC}_{p t}^{\prime}\right)$ and $\mathrm{SSC}_{x s}\left(\mathrm{SSC}_{x s}^{\prime}\right)$ values from $\mathrm{SSC}$ profiles of the Rouse-Vanoni-Ippen equation (García 2008; hereafter, "Rouse equation"), velocity profiles from the von Kármán Prandtl Law for velocity (García 2008), and compare how the ratio of $\frac{\mathrm{SSC}_{x s}^{\prime}}{\mathrm{SSC}_{p t}^{\prime}}$ (i.e., the slope of a $\mathrm{SSC}_{p t}$-to-SSC $\mathrm{SS}_{x s}$ regression) varies with the Rouse number of the Rouse equation (herein, all theoretically derived values are denoted by the superscript " "'"). The Rouse equation can be written as follows (García 2008):

$\operatorname{SSC}_{p t}^{\prime}(z)=\operatorname{SSC}_{p t}^{\prime}(a)\left(\frac{h-z}{z} \frac{a}{h-a}\right)^{R}$

in which 
$R=\frac{\overline{W_{s}}}{\beta \kappa u_{*}}$

$u_{*}=\sqrt{\frac{\tau_{b}}{\rho}}=\sqrt{\frac{C_{d} u^{2}}{2}}$

where:

$\operatorname{SSC}_{p t}^{\prime}(z)=\operatorname{SSC}(\mathrm{mg} / \mathrm{l})$ at elevation $(z)(\mathrm{m})$.

$\operatorname{SSC}_{p t}^{\prime}(a)=\operatorname{SSC}(\mathrm{mg} / \mathrm{l})$ at elevation $(a)(\mathrm{m})$.

$a=$ reference elevation above the bed, equal to $0.1(\mathrm{~m})$.

$h=$ elevation of water surface above bed (i.e., depth) (m).

$R=$ Rouse number (dimensionless).

$\overline{W_{s}}=$ depth-averaged settling velocity $(\mathrm{m} / \mathrm{s})$.

$\beta=$ the inverse turbulent Schmidt number (dimensionless, equal to 1$)$.

$\kappa=$ Von Kármán constant (dimensionless, equal to 0.4).

$u_{*}=$ shear velocity $(\mathrm{m} / \mathrm{s})$.

$\tau_{b}=$ bottom shear stress $\left(\mathrm{N} / \mathrm{m}^{2}\right)$.

$\rho=$ density of fluid $\left(\mathrm{kg} / \mathrm{m}^{3}\right)$.

$C_{d}=$ drag coefficient (dimensionless).

$u=$ fluid velocity $\left(U_{i} ; \mathrm{m} / \mathrm{s}\right)$.

And the von Kármán Prandtl Law for velocity is as follows:

$U^{\prime}(z)=\frac{u_{*}}{\kappa} \log \left(\frac{z}{z_{o}}\right)$

where:

$U^{\prime}(z)=$ fluid velocity at elevation $(z)(\mathrm{m} / \mathrm{s})$.

$z_{o}=$ roughness length (i.e., elevation at which velocity approaches $0(\mathrm{~m})$ ).

A theoretical $\mathrm{SSC}_{x s}, \mathrm{SSC}_{x s}^{\prime}$, assuming uniformly distributed cross-section SSC, was computed as follows:

$\operatorname{SSC}_{x s}^{\prime}=\frac{\int_{z_{o}}^{h} U^{\prime}(z) \operatorname{SSC}_{p t}^{\prime}(z)}{\int_{z_{o}}^{h} U^{\prime}(z)} d z$

where:

$h=$ water depth (m).

Substitution of Eqs. 3 and 6 into Eq. 7 yields the following:

$\operatorname{SSC}_{x S}^{\prime}=\frac{\operatorname{SSC}_{p t}^{\prime}\left(z_{o}\right) \int_{z_{o}}^{h}\left(\frac{h-z}{z} \frac{z_{o}}{h-z_{o}}\right)^{R} \log \left(\frac{z}{z_{o}}\right) d z}{\int_{z_{o}}^{h} \log \left(\frac{z}{z_{o}}\right) d z}$

The slope, $\alpha_{S S C_{p t}(z)}$, of $\operatorname{SSC}_{x s}^{\prime}\left(\operatorname{SSC}_{p t}^{\prime}\right)$ at any elevation $z$ can then be described by normalizing Eq. 8 by Eq. 3 with the following:

$$
\frac{\operatorname{SSC}_{x s}^{\prime}}{\operatorname{SSC}_{p t}^{\prime}(z)}=\frac{\int_{z_{o}}^{h}\left(\frac{h-z}{z} \frac{z_{o}}{h-z_{o}}\right)^{R} \log \left(\frac{z}{z_{o}}\right) d z}{\left(\frac{h-z}{z} \frac{z_{o}}{h-z_{o}}\right)^{R} \int_{z_{o}}^{h} \log \left(\frac{z}{z_{o}}\right) d z}=\alpha_{C(z)}^{\prime}
$$

Equation 9 indicates that the slope of a $\mathrm{SSC}_{p t}$-to-SSC $\mathrm{Sc}_{x s}$ regression will vary with the Rouse number and elevation of the sensor above the bed normalized to $h$. A similar equation can be expressed to analyze how changes in the Rouse number affect the relation between $\mathrm{SSC}_{x s}$ and SSC averaged over any arbitrary range (i.e., $\widehat{\operatorname{SSC}}^{\prime}=\frac{\int_{a}^{b} \operatorname{SSC}_{p t}^{\prime}(a)\left(\frac{h-z-z o}{z h-z_{0}}\right)^{R} d z}{b-a}$ ):

$$
\begin{aligned}
\frac{\operatorname{SSC}_{x s}^{\prime}}{{\widehat{\mathrm{SSC}^{\prime}}}^{\prime}}=\frac{\operatorname{SSC}_{p t}^{\prime}\left(z_{o}\right)(b-a) \int_{z_{o}}^{h}\left(\frac{h-z}{z} \frac{z_{o}}{h-z_{o}}\right)^{R} \log \left(\frac{z}{z_{o}}\right) d z}{\operatorname{SSC}_{p t}^{\prime}(a) \int_{a}^{b}\left(\frac{h-z}{z} \frac{z_{o}}{h-z_{o}}\right)^{R} d z \int_{z_{o}}^{h} \log \left(\frac{z}{z_{o}}\right) d z} \\
=\alpha_{\widehat{\mathrm{SSC}}}^{\prime}
\end{aligned}
$$

Equations 9 and 10 were evaluated for Rouse numbers $(R)$ from 0 to 0.5 with $h$ set to mean water depth at Dumbarton Bridge $(15 \mathrm{~m})$ and $z_{o}$ set to $0.1 \mathrm{~mm}, 1 \mathrm{~mm}$, and $10 \mathrm{~mm}$ with $z_{o}$ set to the range of $z_{o}$ observed by Cheng et al. (1999) in the 15$\mathrm{m}$-deep tidal channel of South Bay. $R$ was then compared to the following: (a) the ratio of $\operatorname{SSC}_{x s}^{\prime}$ to point $\operatorname{SSC}_{p t}^{\prime}(z)$ $\left(\alpha^{\prime} \operatorname{SSC}_{p t}(z)\right)$ computed at 0.1 intervals of $\frac{z}{h}$ from $z_{o}$ to $h$ and (b) the ratio of $\mathrm{SSC}_{x s}$ to depth-averaged SSC averaged from $z_{o}$ to $h$.

\section{Quantifying Changes in Vertical Distribution of SSC}

Inspection of Eqs. 9 and 10 indicates that the ratio of $\mathrm{SSC}_{x s}$ to SSC estimates (i.e., point or depth-averaged measures of SSC) varies with $R$; thus, a correction to $\mathrm{SSC}_{p t}$-to-SSC $\mathrm{SS}_{x s}$ regressions may be needed if $R$ changes with time. To investigate changes in $R$ at Dumbarton Bridge, time series of $R$ were computed by fitting the Rouse equation to SSC estimated from the opticalturbidity measurements taken at two elevations in the water column. The slope of $\operatorname{SSC}_{x s}\left(T_{b}\right)$ was then compared to estimates of $R$ to investigate how changes in the vertical distribution of SSC affect field-based estimates of $\mathrm{SSC}_{x s}$. At least two $\mathrm{SSC}_{p t}(z)$ are needed to estimate $R . R$ is computed by fitting an ordinary least squares regression to the $\log _{10}$-tranformed $\operatorname{SSC}_{p t}(z)$ values estimated from $T_{b}$ readings at each senor, that is as follows:

$\log \left(\operatorname{SSC}_{p t}(z)\right)=R\left(\frac{h-z}{z} \frac{z_{o}}{h-z_{o}}\right)+\log \left(\operatorname{SSC}_{p t}(a)\right)$

Uncertainty intervals on $R$ from uncertainty in the prediction of $\mathrm{SSC}_{p t}$ from $T_{b}$ were quantified using bootstrapped uncertainty estimates of $\mathrm{SSC}_{p t}$. Bootstrapped uncertainty estimates of $\mathrm{SSC}_{p t}$ at the mid-depth and near-bed sensors were developed from regressions between $T_{b}$ readings and bottle samples of $\mathrm{SSC}_{p t}$ collected at each sensor from WY 2009 2016 (Buchanan et al. 2018) using the methods of Rustomiji and Wilkinson (2008) (see section 1 of the supplemental text for uncertainty computation details). The uncertainty in $\mathrm{SSC}_{p t}$ 
time series is incorporated in $R$ by computing quantiles from all possible $R$ estimates from all combinations of $\mathrm{SSC}_{p t}$ quantiles at $0.05,0.16,0.5,0.84$, and 0.95 (i.e., \pm 1 and $2 \sigma$ and the median quantile).

We acknowledge that two data points for an equation fit is not ideal; however, the optical turbidity measurements taken at two elevations in the water column are part of a long-term monitoring program in the SFE and were the only way to obtain time series of the $R$ when $\mathrm{SSC}_{x s}$ data were collected. Estimates of $R$ based on $\mathrm{SSC}_{p t}$ at the near-bed and mid-depth sensor were validated using 199 vertical SSC profiles collected from 2008 to 2018 by Schraga and Cloern (2017) and Schraga et al. (2018). The 2008-2018 SSC profiles were collected at a station $390 \mathrm{~m}$ north of Dumbarton Bridge in the 15-m-deep channel as part of a long-term water quality monitoring program in the SFE. The SSC profiles are estimated from turbidity measurements reported at $1 \mathrm{~m}$ intervals starting at $1 \mathrm{~m}$ above the bed. Two estimates of $R$ were computed from the 199 SSC profiles using the following: (1) Eq. 3 fit to an entire SSC profile (typically 10 data points) and (2) Eq. 3 fit to SSC estimates at $1 \mathrm{~m}$ and $7 \mathrm{~m}$ from the bed. $R$ estimates using the entire SSC profile and only two data point are proportional with $R$ computed from 2 points predicting $R$ based on all profile data with a slope of 1.1, intercept of $0.0, r^{2}$ of 0.8 , and $p$ value $<0.0001$.

To evaluate the applicability of the Rouse equation at Dumbarton Bridge, the equation was fit to continuous sediment concentration profiles from two datasets: (1) 43 crosschannel transects of acoustic Doppler current profile (ADCP) acoustic backscatter data converted to SSC collected during February $28(n=3)$, April 17-18 $(n=24)$, and September 25 $(n=16), 2018$ and (2) the 199 vertical SSC profiles collected from 2008 to 2018. The ADCP data were collected in the same cross section where the US D-96 $\mathrm{SSC}_{x s}$ measurements were collected. The ADCP backscatter data were corrected for two-way transmission loss and converted to SSC using a regression between acoustic backscatter data and 54 water samples of SSC $\left(r^{2}<0.74, p\right.$ value $\left.<0.0001\right)$.

Following validation of the applicability of the Rouse equation at Dumbarton Bridge (see "Results" below), sediment-flux estimates at the mid-depth and near-bed sensors that do and do not account for changes in $R$ were compared to evaluate the importance of accounting for changes in the vertical distribution of SSC at different points within the water column. Changes in $R$ were accounted for in sediment flux estimates by time series of $\alpha^{\prime}{ }_{\mathrm{SSC}_{p t}(z)}$ (i.e., the slope of $\left.\operatorname{SSC}_{x s}\left(\operatorname{SSC}_{p t}\right)\right)$. Note that Eq. 3 assumes laterally uniform cross-channel SSC; $\alpha^{\prime}{ }_{\text {SSC }_{p t}(z)}$ and $\alpha^{\prime} \widehat{\text { SSC }}$ computed from Eqs. 9 and 10 may differ from field-based observations of $\alpha^{\prime}{ }_{\mathrm{SSC}_{p t}(z)}$ if cross-channel SSC is not distributed uniformly. Analysis of SSC samples from the Equal-Discharge Increment samples used to compute $S S C_{x s}$ indicates that SSC is elevated on the eastern edge of the channel relative to $\mathrm{SSC}_{x s}$. The median of Equal-Discharge Increment sample SSC normalized to $\mathrm{SSC}_{x s}$ at the eastern edge of the channel is 1.2 while the median of all other sampling locations range between 0.90 and 0.94 . The lateral asymmetry in cross-channel SSC was the same for flood and ebb tides and did not vary with water velocity or depth. Below we utilize an empirical estimate of Eq. 9 (see Eq. 14) because cross-channel SSC is not distributed uniformly.

\section{Accounting for Changes in the Vertical Distribution of SSC in Suspended Sediment Flux Measurements}

$\mathrm{SSC}_{x s}$ estimates that do not account for changes in $R$, that is a regression with a fixed slope between an SSC surrogate (herein, turbidity measured at-a-point) and $\mathrm{SSC}_{x s}$, were computed using the following:

$\operatorname{SSC}_{x S}\left(T_{b}\right)=m_{1} T_{b}+b_{1}$

$\mathrm{SSC}_{x s}$ estimates that account for changes in $R$ were computed using the following:

$\operatorname{SSC}_{x s}\left(T_{b}, R, \frac{z}{h}\right)=m_{2} T_{b}+b_{2}$

and

$m_{2}\left(R, \frac{z}{H}\right)=m_{3} \frac{1}{\frac{c 1}{h} R}+b_{3}=\alpha_{\operatorname{SSC}_{p t}(z)}$

where:

$z_{i}=$ elevation of sensor used to measure $T_{b}(\mathrm{~m})$.

Combining Eqs. 13 and 14 yields the following:

$\operatorname{SSC}_{x s}\left(T_{b}, R, \frac{z}{H}\right)=m_{3} T_{b}{\frac{z_{i} R^{c 1}}{h}}+T_{b} b_{3}+b_{2}$

The inclusion of $\frac{z_{i}}{h}$ in Eq. 14, the empirical estimate of Eq. 9 , was needed because the elevation of the sensors used to measure $T_{b}$ is fixed while $h$ varies in time. Missing $T_{b}$ data at the mid-depth sensor and $R$ time series were infilled to allow comparison of cumulative $Q_{s}$ estimates to previous studies in LSB (Shellenbarger et al. 2013) and to LSB accretion estimates from bathymetric surveys (Jaffe and Foxgrover 2006). Data gaps occurred due to biofouling or sensor failure. For details on in-filling of missing data, the reader is referred to section 2 of the supplemental text.

\section{Investigation of Flocculation on Rouse Number Time Series and SSC Estimates}

Depth-averaged $W_{s}\left(\overline{W_{s}}\right)$ and point $W_{s}$ at each sensor were computed to investigate the controls of flocculation on $R$ and SSC estimated from turbidity data. $R$ is expected to vary with not only water velocity but also with $W_{s}$ of cohesive sediment. 
Because changes in particle size driven by flocculation have been shown to impact SSC estimates from optical turbidity measurements (e.g., Downing (2006), Sahin et al. (2017b)), point $W_{s}$ time series and observations were needed to evaluate if changes in flocculation resulted in biased SSC from estimates $T_{b}$.

Depth-averaged $W_{s}, \overline{W_{s}}$, is computed using $R$ in Eq. 4 and a $C_{d}$ value of 0.002 from Elias et al. (2013). We assume that $C_{D}$ does not systematically covary with the tides and utilize a constant $C_{D}$ of 0.002 computed from the calibrated hydrodynamic model of Elias et al. (2013). A tidal asymmetry in $C_{D}$ could induce an artificial asymmetry in $\overline{W_{s}}$. The drag coefficient, $C_{D}$, may vary with the influence of wave orbitals, bed sediment grain size, and bed-form geometry (Bricker et al. 2005). Wind waves would not affect $C_{D}$ in the 15 -m-deep channel at Dumbarton Bridge. Further, the channel bed $5 \mathrm{~km}$ north and south of Dumbarton bridge is composed of clay and fine silt (McGann et al. 2013); thus, bed grain-size changes and large-scale bedforms (i.e., greater than ripples) that do not form on muddy beds are not expected to induce systematic changes in $C_{D}$ with the tide.

Point $W_{s}$ time series at each sensor were computed from the sediment transport equation considering only vertical turbulent mixing and longitudinal advection:

$$
\begin{aligned}
\frac{\partial \mathrm{SSC}_{p t}(z)}{\partial t}= & W_{s} \frac{\partial \mathrm{SSC}_{p t}(z)}{\partial z} \\
& +\frac{\partial}{\partial z} K \frac{\partial \mathrm{SSC}_{p t}(z)}{\partial z}-\frac{\partial u \mathrm{SSC}_{p t}(z)}{\partial x}
\end{aligned}
$$

where:

$\operatorname{SSC}_{p t}(z)=\operatorname{SSC}(\mathrm{mg} / \mathrm{l})$ at elevation $(z)(\mathrm{m})$.

$t$ is time.

$W_{s}$ is settling velocity $(\mathrm{m} / \mathrm{s})$.

$z$ is elevation above the bed $(\mathrm{m})$.

$K$ is eddy diffusivity $\left(\mathrm{m}^{2} / \mathrm{s}\right)$.

$u$ is longitudinal (i.e., along the channel) water velocity (flood positive, $\mathrm{m} / \mathrm{s}$ ).

$x$ is the longitudinal coordinate (flood positive, $\mathrm{m}$ ).

The first and second terms on the right-hand side are the settling and vertical turbulent mixing terms, respectively. The third term is longitudinal advection. Using the product differentiation rule, settling velocity from Eq. 16 is as follows:

$$
W_{s}=\frac{\frac{\partial \operatorname{SSC}_{p t}(z)}{\partial t}-K \frac{\partial^{2} \operatorname{SSC}_{p t}(z)}{\partial z^{2}}-\frac{\partial K}{\partial z} \frac{\partial \operatorname{SSC}_{p t}(z)}{\partial z}+u \frac{\partial \operatorname{SSC}_{p t}(z)}{\partial x}}{\frac{\partial \operatorname{SSC}_{p t}(z)}{\partial z}}
$$

Equation 17 provides point estimates of $W_{s}$ at each sensor elevation (see section 3 of the supplemental text for details on the computation of each term). Point $W_{s}$ estimates were validated using in situ measurements of $W_{s}$ collected at the mid-depth sensor using the "floc-cam" of Manning et al. (2007, 2017), which was based on the INSSEV system of Manning and Dyer (2002), during a 3-day, spring-tide, deployment from April 16 to 18, 2018. Seven floc-cam measurements were collected on April 18, 2018 from late ebb into flood. Floc-cam measurements provide the size, density, and settling velocity of numerous flocs per sample. To provide one $W_{s}$ measurement to compare to $W_{s}$ estimates, a mass-weighted $W_{s}$ was computed following Eq. 2 of Manning and Schoellhamer (2013). The uncertainty in $\mathrm{SSC}_{p t}(z)$ time series is incorporated by computing quantiles from all possible $W_{s}$ estimates from all combinations of $\operatorname{SSC}_{p t}(z)$ quantiles at $0.05,0.16,0.5,0.84$, and 0.95 (i.e., \pm 1 and $2 \sigma$ and the median quantile).

The same turbidity probe model and settings were utilized during the April deployment as the long-term deployment; however, the probes were set to sample every $30 \mathrm{~s}$ instead of every $15 \mathrm{~min}$ (900 s). The higher frequency sampling interval was chosen to ascertain if the 15-min sampling interval used in the long-term deployment was sufficient to characterize the $\frac{\partial \operatorname{SSC}_{p t}(z)}{\partial t}$ term of Eq. 17. For comparison to the long-term deployment, $W_{s}$ estimates were also computed using a sampling interval of $900 \mathrm{~s}$ by subsampling the $30 \mathrm{~s}$ time series every $15 \mathrm{~min}$.

\section{Results}

The WY2013-2016 regressions for $U_{x s}\left(U_{i}\right)$ and $A_{x s}(p)$ (not shown) were linear and exhibited no statistically significant difference in slope or intercept compared to regressions in WY 2009-2011 (Shellenbarger et al. 2013). The reader is referred to Shellenbarger et al. (2013) for plots of $U_{x s}\left(U_{i}\right)$ and $A_{x s}(p)$. Evaluation of Eqs. 9 and 10 indicates that the ratio between $\mathrm{SSC}_{x S}$ and point or depth-averaged SSC measurement covaries with the vertical distribution of SSC as measured by $R$ (Fig. $3 \mathrm{~b}, \mathrm{c}$ ). The roughness length, $z_{o}$, affects the ratio between $\mathrm{SSC}_{x S}$ and SSC measurement but has a secondary effect to $R$ and the elevation from which the SSC is estimated (Fig. 3b, c). Field observations follow the theoretical results of Eq. 9 with $R$ proportional to $\frac{\mathrm{SSC}_{x s}}{T_{b}}$ at the mid-depth sensor and $R$ inversely proportional to $\frac{\mathrm{SSC}_{x s}}{T_{b}}$ at the near-bed sensor (Fig. 4c, f).

Application of Eq. 15 to compute sediment flux requires that the Rouse equation is applicable during the time wherein most of sediment flux is occurring. Sediment concentration profiles from 40 of the 43 ADCP transects exhibited concentration profiles predicted by the Rouse equation with $r^{2}$ values between 0.87 and 0.99 . The interquartile range of $r^{2}$ values from the Rouse equation fit to all data in each SSC profiles 


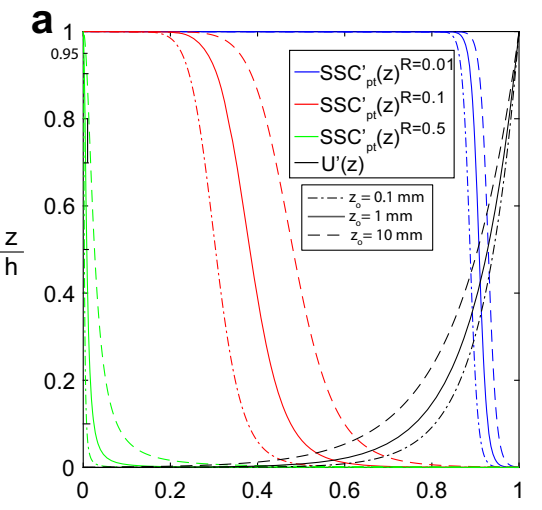

Water velocity (U) or suspended sediment concentration (SSC) normalized to maximum $U$ or SSC, respectively

Fig. 3 a Theoretical suspended-sediment concentration (SSC) profiles from the Rouse equation (Eq. 3) and velocity profiles from the von Karman Prandtl Law for velocity (Eq. 6). SSC and velocity profiles computed using range of observed roughness length $\left(z_{o}\right)$ in South Bay with reference elevation $(a)$ in Eq. 3 set to $z_{o}$ for each SSC profile. b, $\mathbf{c}$ Change in slope between velocity-weighted cross-sectional average $\left(\mathrm{SSC}_{x s}\right.$; see
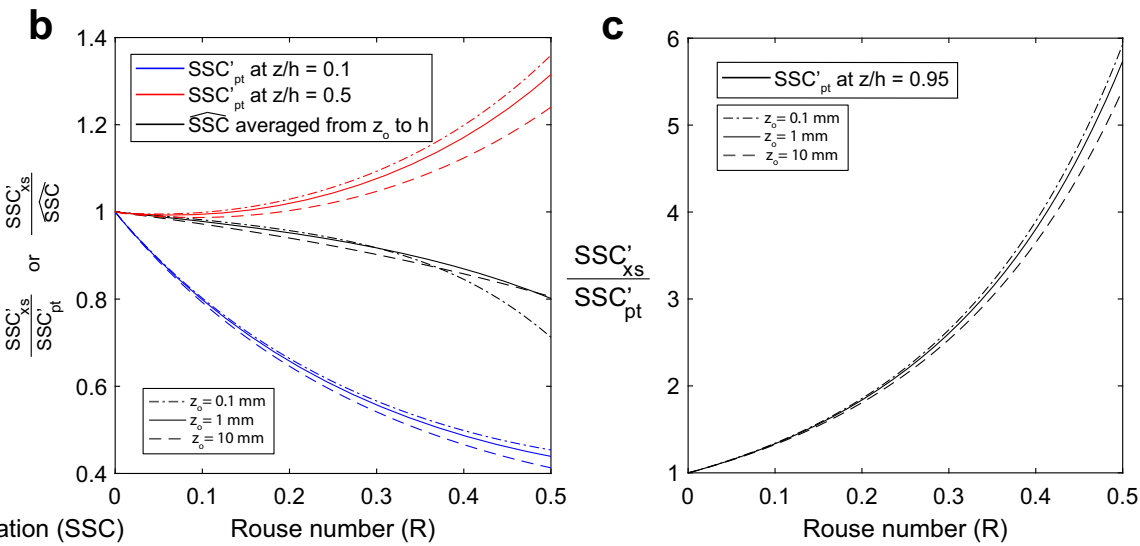
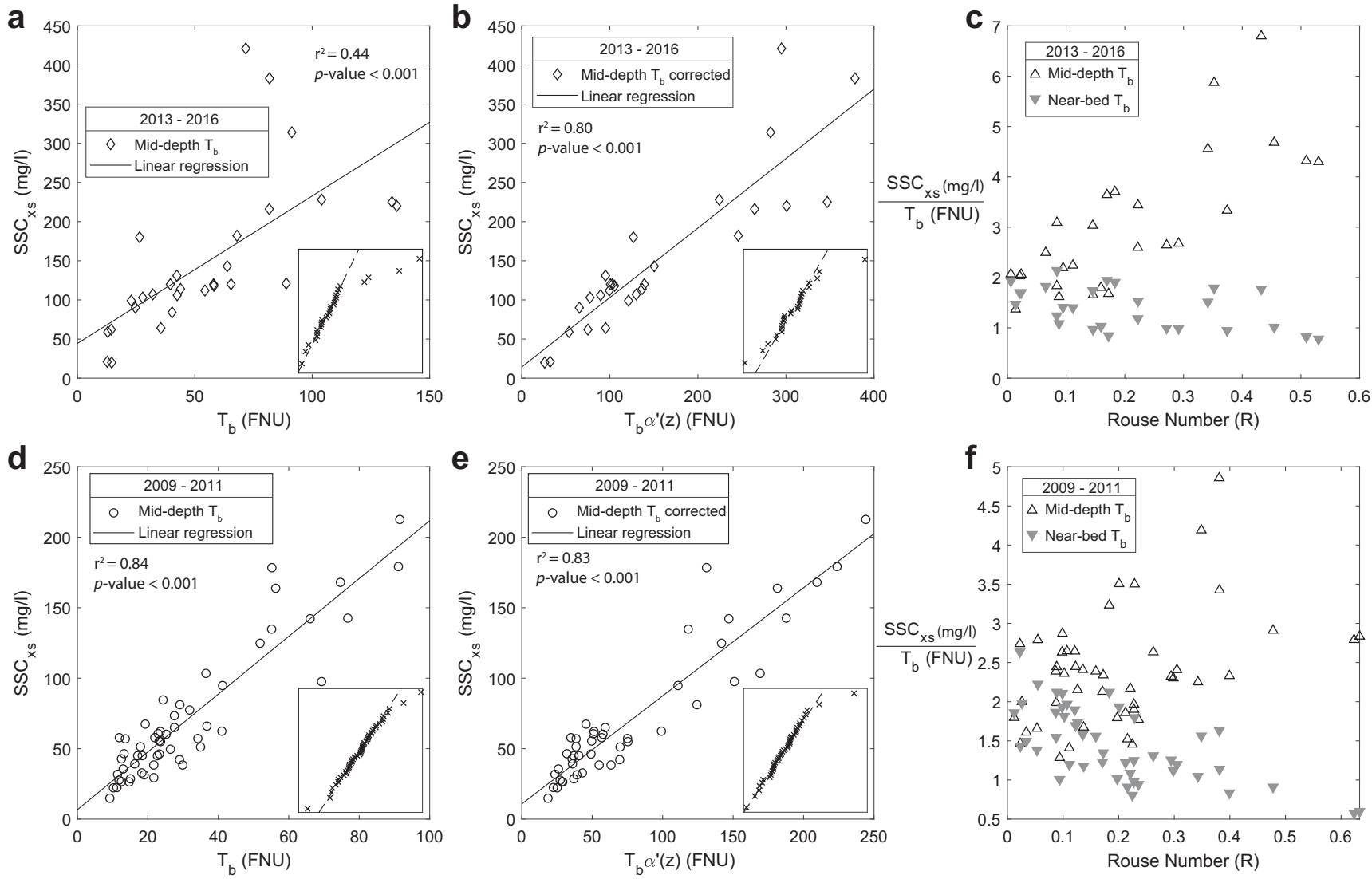

e

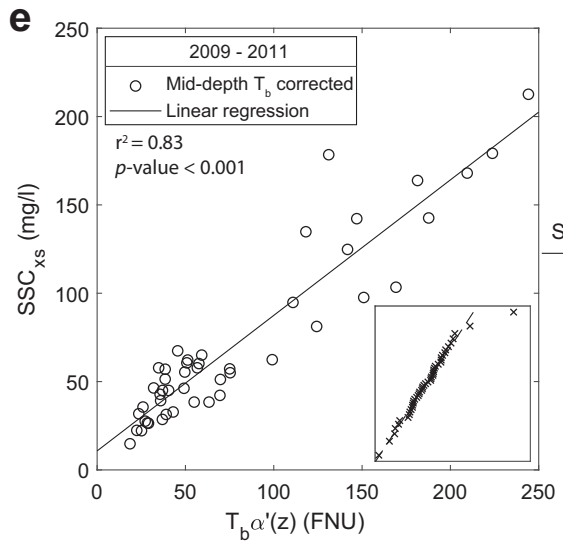

Eq. 7) and various estimates of SSC $(C)$ as a function of Rouse number $(R)$. $\mathrm{SSC}_{x s}$ and SSC computed from profiles in a. Note effect of changing $R$ varies depending upon location of $C$ estimate in water column with bias increasing towards the bed and water surface. Note also that depthaveraged estimates of $C$ may be biased by unaccounted -for vertical changes in SSC
Fig. 4 a, $\mathbf{d}$ Turbidity $\left(T_{\mathrm{b}}\right)$ at the mid-depth sensor and velocity-weighted cross-section averaged suspended-sediment concentration $\left(\mathrm{SSC}_{x s}\right)$ data for 2009-2011 and 2013-2016. b, e $T_{\mathrm{b}}$ at the mid-depth sensor corrected for vertical changes in SSC profile using Eq. 15. Inset: normal probability plots comparing the distribution of regression residuals to a normal distribution (dashed line) shown in $\mathbf{a}, \mathbf{b}, \mathbf{d}$, and e. Data departing from a normal distribution will plot off the dashed line. Inset axes are unlabeled, the $x$-axis is regression residual in milligrams per liter, and the $y$-axis is the cumulative probability from 0 to 1 . c, f Relation between Rouse number
$(R)$ and ratio of $\frac{\mathrm{SSC}_{x s}}{T_{\mathrm{b}}}$ at the mid-depth and near-bed sensors. Observed relation between $R$ and $\frac{\mathrm{SSC}_{x s}}{\mathrm{~T}_{\mathrm{b}}}$ (i.e., $\alpha_{C(z)}$ of Eq. 9) follows theoretical predictions ( $\alpha_{C(z)}$ from Eq. 9; see Fig. 3b), but rate of change between $R$ and $\frac{\mathrm{SSC}_{x s}}{T_{\mathrm{b}}}$ is higher at mid-depth sensor. Note difference between $\alpha_{C(z)}$ and $\alpha_{C(z)}$ remains the same when $T_{b}$ is converted to a point estimate of $\operatorname{SSC}\left(\right.$ i.e., $\left.\frac{\mathrm{SSC}_{x s}}{C(z)}\right)$ 
collected by Schraga et al. (2018) from 2008 to 2018 ranged from 0.73 to 0.90 with $90 \%$ of all profiles exhibiting $r^{2}$ values $>0.5$. The remaining sediment concentration profiles from 3 of the 43 ADCP transects did not follow predictions of the Rouse equation $\left(r^{2}<0.4\right)$. Visual inspection of the specific conductance records from sensors at the mid-depth and nearbed elevations indicate stratified salinity conditions during the collection of 3 ADCP transects. The Rouse equation assumes uniform flow and does not account for estuarine variability such as stratification and reversing flows. Visual inspection of specific conductance records from sensors at the mid-depth and near-bed elevations during WY 20092016 indicates that stratification in the channel is primarily limited to tributary inflow events and decreased tidal energy consistent with Lucas et al. (2009). Reversing flows occur at the end of slack tide when $\mathrm{SSC}_{x s}, Q_{x s}$, and thus $Q_{s}$ minima are observed. Given limited stratification and decreased sediment flux at reversing flows, use of the Rouse equation is reasonable for the time wherein most of sediment flux is occurring.

$\mathrm{SSC}_{x s}\left(T_{b}\right)$ regression data using linear and logtransformed data exhibited heteroscedastic residuals at the mid-depth and near-bed sensors with WY 20132016 data exhibiting increased scatter relative to the WY 2009-2011 dataset (Fig. 4a, d). Including $R$ in the prediction of $\mathrm{SSC}_{x s}$ using Eq. 15 reduced scatter in the WY 2013-2016 dataset ( $r^{2}$ of 0.44 changed to $r^{2}$ of 0.80 ; Fig. $4 \mathrm{a}, \mathrm{b}$ ) but did not improve scatter in the WY2009-2011 dataset ( $r^{2}$ of 0.84 changed to $r^{2}$ of 0.83 ; Fig. $4 \mathrm{~d}$, e). Including $R$ in the prediction of

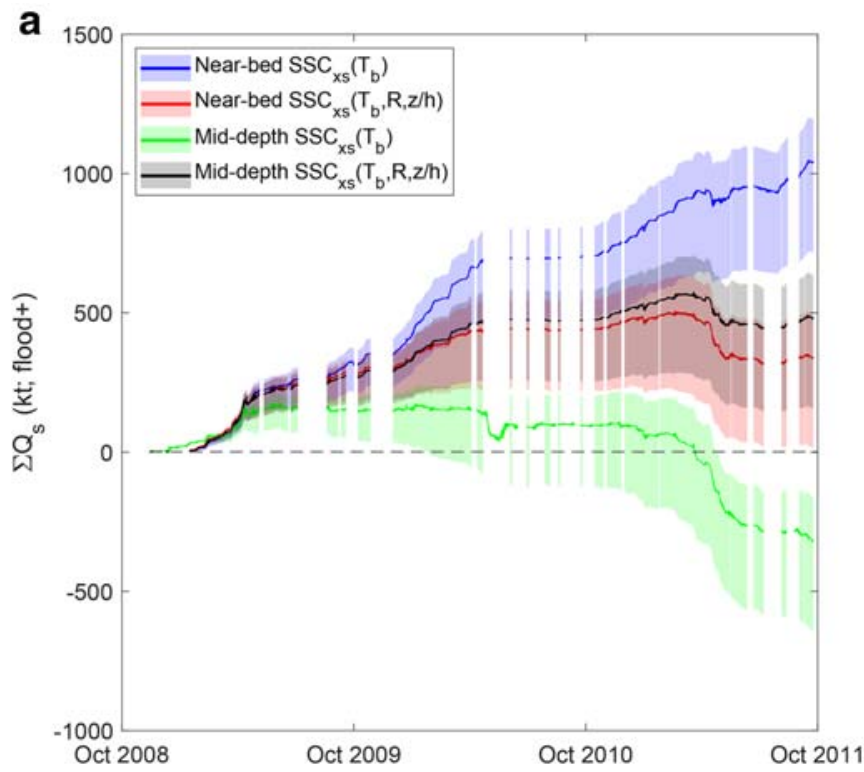

Fig. 5 a, b Cumulative sediment flux ( $\sum Q_{s}$ ) for WY 2009-2011 and WY

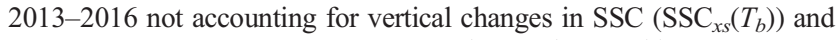
accounting for vertical changes in $\operatorname{SSC}\left(\left(\operatorname{SSC}_{x s}\left(T_{b}, R, \frac{z}{h}\right)\right)\right.$ with no missing data infilled. The gap in data from December 2015 to April 2016
$\mathrm{SSC}_{x s}$ resulted in more normally distributed residuals in the WY 2009-2011 and WY 2013-2016 datasets (Fig. 4 a, b, d, and e).

Application of Eq. 15 to compute $\sum Q_{s}$ brings estimates from mid-depth sensor and near-bed sensor into agreement (Fig. 5). At the mid-depth sensor, accounting for vertical changes in SSC using Eq. $15\left(\operatorname{SSC}_{x S}\left(T_{b}, R, \frac{z}{H}\right)\right)$, compared to the typically utilized regression $\left(\operatorname{SSC}_{x s}\left(T_{b}\right)\right)$ that does not account for vertical changes in SSC, changes the sign of $\sum Q_{s}$ from sediment export (i.e., net seaward sediment flux) to sediment import (i.e., net landward sediment flux) for WY 2009-2011 and WY 2013-2016 (Fig. 5). The change in $\sum Q_{s}$ sign at the mid-depth sensor occurs with and without missing data (Fig. 6b), and the change in $\sum Q_{s}$ magnitude for each WY is statistically significant (Fig. 6b). At the near-bed sensor, $\sum Q_{s}$ estimates do not change sign but the change in $\sum Q_{s}$ estimates for WY 2009-2011 and WY 2013-2016 is statistically significant (Fig. 5). $\sum Q_{s}$ magnitude and direction computed from $\operatorname{SSC}_{x s}(T)$ and $\operatorname{SSC}_{x s}\left(T_{b}, R, \frac{z}{H}\right)$, at the mid-depth and near-bed sensors, are insensitive to model transformations, while uncertainty decreased for those transformations that maximized residual homoscedasticity.

During WY 2009, 2010, and 2013-2016, sediment was imported into LSB; during WY 2011 and 2013, sediment export and import were approximately balanced (Fig. 6b). Tributary sediment fluxes during WY 2009-2011 (45 kt/ year; McKee et al. 2013) and WY 2013-2016 (48 kt/year) were an order of magnitude less than sediment fluxes observed at Dumbarton Bridge (Fig. 5). LSB basin-wide sediment accumulation can be estimated using a dry bulk density $\left(617 \mathrm{~kg} / \mathrm{m}^{3}\right.$;

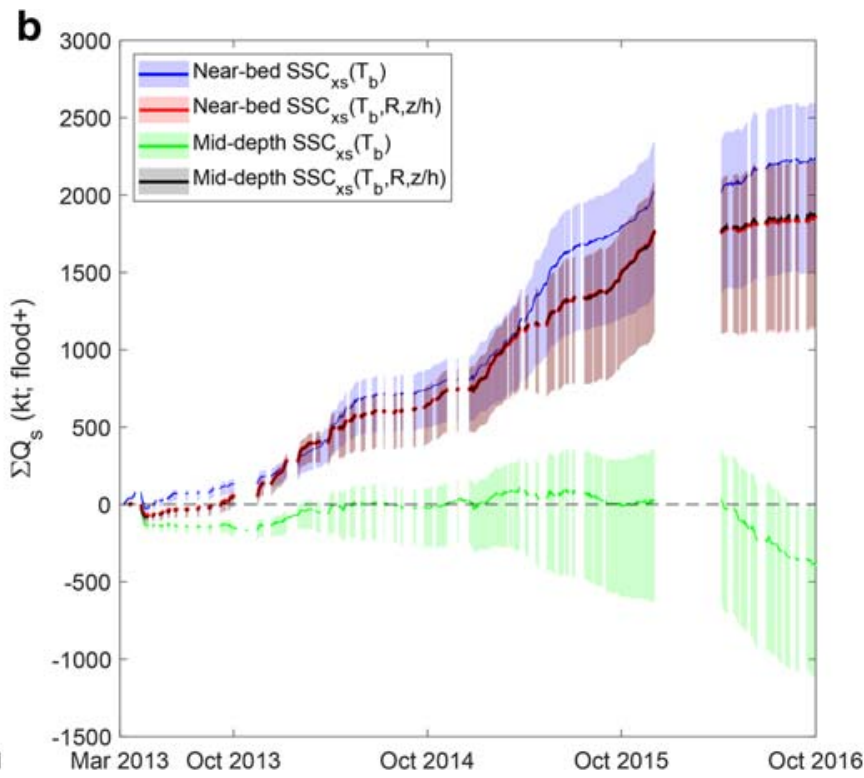

resulted from ADCP servicing. Outer lines are 95\% confidence intervals. Note proposed correction brings $\sum Q_{s}$ at the mid-depth and nearbed sensors into agreement 

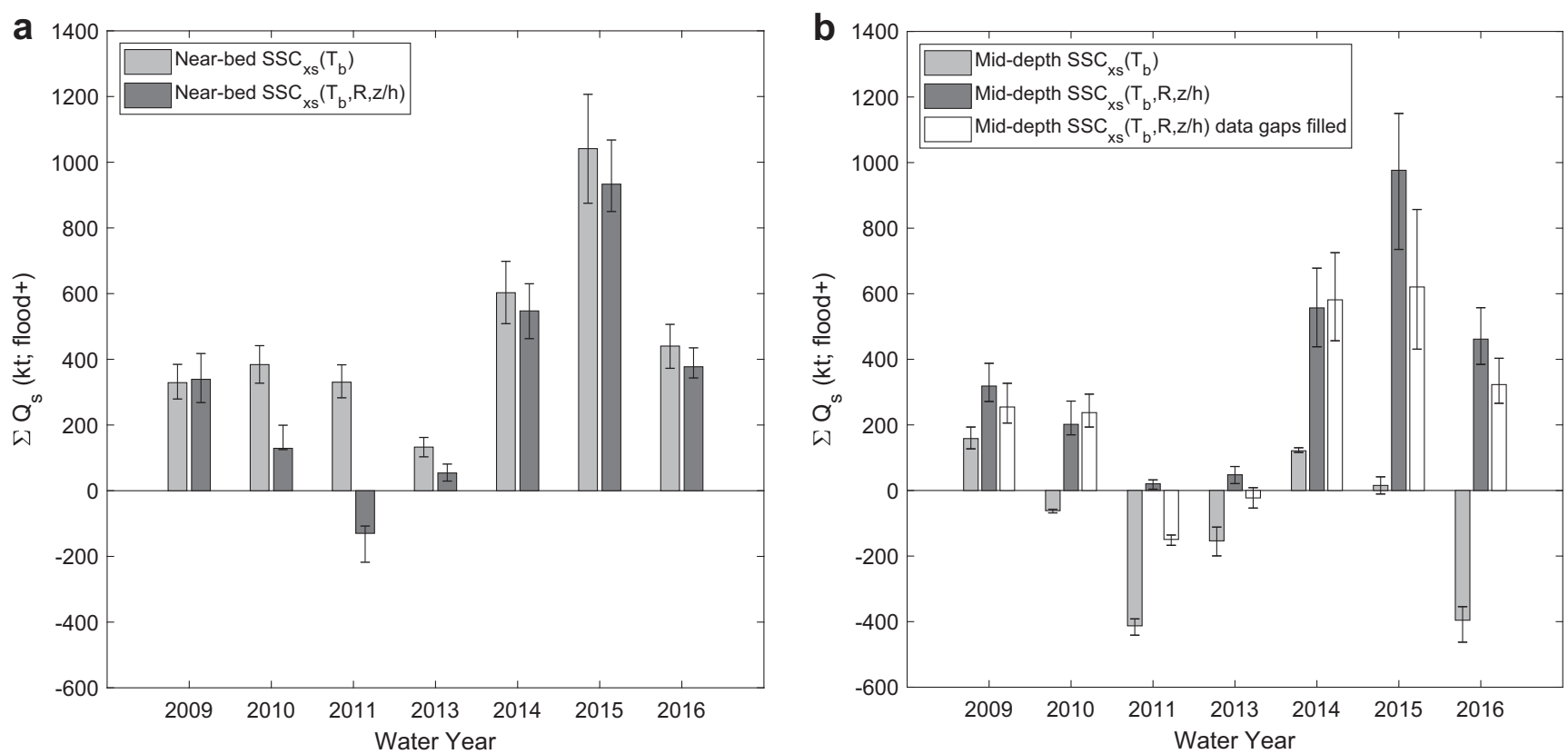

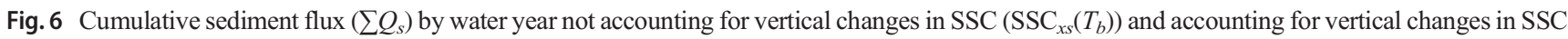
$\left(\left(\operatorname{SSC}_{x s}\left(T_{b}, R, \frac{z}{h}\right)\right)\right.$ at the near-bed sensor (a) and mid-depth sensor (b). Lines on each bar indicate $95 \%$ confidence range

the mean dry bulk density of 7 cores collected in South Bay; Caffrey 1995; Love et al. 2003) and area of the basin $\left(34 \mathrm{~km}^{2}\right.$ at mean tide level; Hager and Schemel 1996) resulting in roughly $21 \mathrm{kt}$ per $1 \mathrm{~mm}$ of deposition in LSB. Sediment fluxes for WY 2009, 2010, and 2011 computed with missing data infilled at the mid-depth sensor would result in accretion rates of $12 \pm 3 \mathrm{~mm}, 11 \pm 3 \mathrm{~mm}$, and $-7 \pm 1 \mathrm{~mm}$, respectively, with negative values indicating erosion. Sediment flux for WY 2014,2015 , and 2016 would result in accretion rates of $28 \pm$ $7 \mathrm{~mm}, 30 \pm 11 \mathrm{~mm}$, and $15 \pm 4 \mathrm{~mm}$, respectively. WY 2013 was excluded from accretion rate comparisons since data collection began 5 months into WY 2013 in March 2013. The magnitude of computed flux and accretion rates reported above are within flux and accretion rates computed from bathymetric surveys south of Dumbarton Bridge from 1983 to 2005 (Jaffe and Foxgrover 2006). From 1983 to $2005,16 \pm 1.2 \times 10^{6} \mathrm{~m}$ of sediment was deposited south of Dumbarton Bridge and assuming the same bulk density, above average annual sediment flux into LSB from 1983 to 2005 was $449 \mathrm{kt} /$ year with an average annual accretion rate of $20 \mathrm{~mm} /$ year (Jaffe and Foxgrover 2006). The average annual sediment flux and accretion rate from WY 2009-2011 and WY 2014-2016 was $311 \mathrm{kt} /$ year and $15 \mathrm{~mm} /$ year, respectively.

$R$ and $\overline{W_{S}}$ time series from 2009 to 2011 and 2013-2016 covary with spring and neap tidal phases (not shown) and follow semidiurnal tidal fluctuations (Figs. 7 and 8). Maxima in $R$ and $\overline{W_{s}}$ occur prior to peak $U_{x s}$ with maxima higher on flood than ebb tides (Figs. 7 and 8). Higher water velocity on flood tide, proportional to the denominator of $R$ in Eq. 4, indicates that larger $R$ on flood tides is the result of higher $\overline{W_{s}}$ on flood compared to ebb tides (Fig. 9). Larger $\overline{W_{s}}$ on flood tide agrees with Gartner et al. (2001), who observed larger floc sizes on flood tide than ebb tide. Time series of $R$ and all measures of $W_{s}$ (i.e., $\overline{W_{s}}$, point $W_{s}$ measurements from floc-cam at the mid-depth sensor, and point $W_{s}$ estimates time series) increase with $U_{x s}$ up to $\sim 0.5 \mathrm{~m} / \mathrm{s}$ (Fig. 8). Above $U_{x s}$ values of $\sim 0.5 \mathrm{~m} / \mathrm{s} R$ and measures of $W_{s}$ decrease (Figs. 8 and 10a).

Point $W_{s}$ estimates (Eq. 17) and depth-averaged settling velocity estimates $\left(\overline{W_{s}}\right.$; Eq. 4) for the April 2018 data were computed using $\operatorname{SSC}_{p t}(z)$ estimates from 2 (near-bed and middepth), 3 (near-bed, lower, and mid-depth), or 4 (near-bed, lower, mid-depth, and upper) sensors and sampling intervals of 900 and $30 \mathrm{~s}$. Point $W_{s}$ estimates at the mid-depth sensor $\left(W_{s} 7 \mathrm{~m}\right)$ exhibit excellent agreement $\left(r^{2}>0.96, p\right.$ value $<$ $0.0001)$ with floc-cam $W_{s}$ measurements when using $\mathrm{SSC}_{p t}(z)$ estimates from 2 or 3 sensors and a sampling interval of $30 \mathrm{~s}$ (Fig. 10b). The slope between floc-cam $W_{s}$ measurements and $W_{s}$ estimates is less than 1 because floc-cam cannot detect flocs less than $\sim 16 \mu \mathrm{m} . \overline{W_{s}}$ and point $W_{s}$ time series at the near-bed, mid-depth, and upper sensor, computed using $\mathrm{SSC}_{p t}(z)$ estimates from 2 or 3 sensors and a sampling interval of $30 \mathrm{~s}$, covary $\left(r^{2}>0.95, p\right.$ value $\left.<0.0001\right)$, with differences primarily occurring near slack tide (Fig. 8). Increases in point $W_{s}$ time series at slack tide are consistent with flocculation induced by interparticle collision of settling particles.

Point $W_{s}$ estimates are sensitive to sampling interval (900 s versus $30 \mathrm{~s})$ and whether $\operatorname{SSC}_{p t}(z)$ estimates from the nearsurface sensor at $12 \mathrm{~m}$ were used to estimate the $\frac{\partial \mathrm{SSC}_{p t}(z)}{\partial z}$ term of Eq. 17. Point $W_{s}$ estimates using $\mathrm{SSC}_{p t}(z)$ estimates from 
Fig. 7 Cross-section averaged water velocity $\left(U_{x s}\right)$, the Rouse number $(R)$ from Eq. 3, and depth-averaged settling velocity $\overline{W_{s}}$ from Eq. 4 plotted as a function of tidal phase. Tidal phase was computed following Eq. 1 of Downing-Kunz and Schoellhamer (2013) with $U_{x s}$ and slack after flood tide set to $0^{\circ}$ and slack after flood set to $360^{\circ}$. Slack after ebb tide occurs near $180^{\circ}$ due to tidal asymmetry. All data from 2009 to 2016 is binned into $5^{\circ}$ bins. The interquartile ranges (shaded regions) and median values (solid and dashed lines in $\mathbf{a}$ and $\mathbf{b}$ and data in $\mathbf{c}$ and d) are shown a

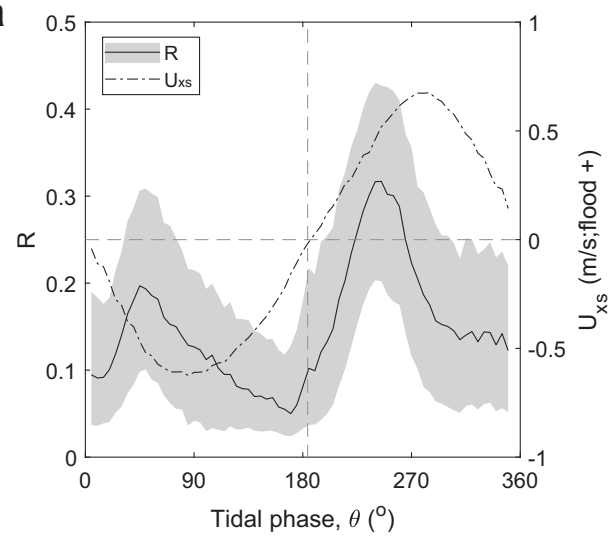

C

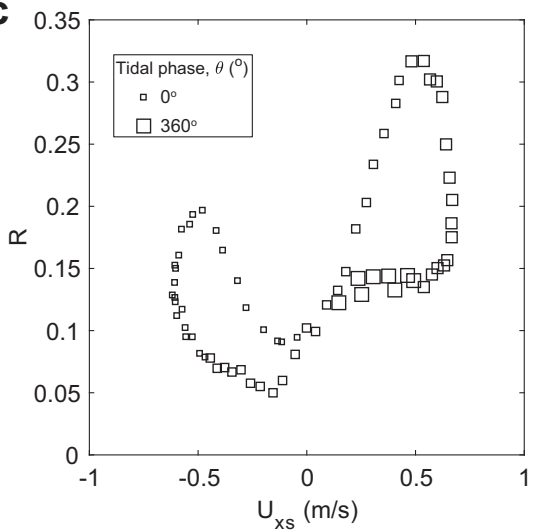

b

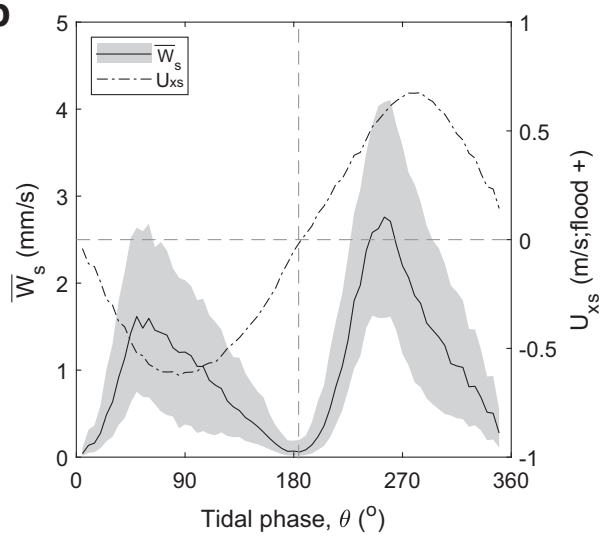

d

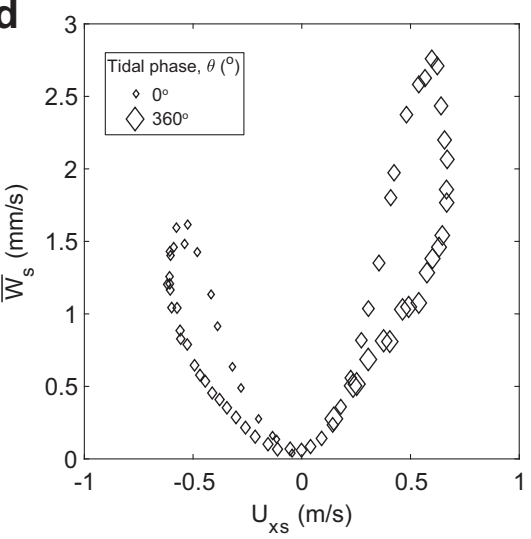

the near-surface sensor and/or a sampling interval of $900 \mathrm{~s}$, that is the sampling interval of the long-term deployment, resulted in $W_{s} 7 \mathrm{~m}$ estimates that exhibited no statistically significant relation to floc-cam $W_{s}$ measurements. The sensitivity of point $W_{s}$ estimates to sampling interval suggests that the long-term deployment sampling interval of $900 \mathrm{~s}$ is not sufficient to characterize the $\frac{\partial \mathrm{SSC}_{p t}(z)}{\partial t}$ term of Eq. 17.

Depth-averaged $W_{s}, \overline{W_{s}}$, was insensitive to the sampling interval but inclusion of $\operatorname{SSC}_{p t}(z)$ estimates from the nearsurface sensor at $12 \mathrm{~m}$ above the bed resulted in point and depth-averaged $W_{s}$ estimates that exhibit little to no correlation with floc-cam $W_{s}$ measurements $\left(r^{2}<0.1, p\right.$ value $\left.>0.5\right)$. The agreement between $W_{s} 7 \mathrm{~m}$ computed using $\operatorname{SSC}_{p t}(z)$ estimates from the near-surface sensor and floc-cam $W_{s}$ did not improve by changing the form of $K(z)$ in Eq. 17 (see section 3 of the supplemental text). The lack of agreement between $W_{s} 7 \mathrm{~m}$ computed using $\operatorname{SSC}_{p t}(z)$ estimates from the near-surface sensor and floc-cam $W_{s}$ may be driven by vertical changes in the turbidity-to-SSC regression parameters or violation of the Rouse equation near the water surface. Advection (i.e., the $\frac{\partial \operatorname{SSC}_{p t}(z)}{\partial x}$ term of Eq. 17) was not included in $\overline{W_{s}}$ or point $W_{s}$ estimates because advection accounted for only $2 \%$ of the settling velocity estimates and inclusion of the advection term did not improve the agreement with floc-cam $W_{s}$ measurements (Fig. 10b).
The ratio of point SSC and turbidity measured at the middepth sensor shows no statistically significant relation with floc-cam $W_{s}$ measurements $\left(r^{2}=0.25 ; p\right.$ value $\left.=0.3\right)$. The ratio of point SSC and turbidity at the near-bed sensor also shows no statistically significant relation with point $W_{s}$ estimates at the near-bed sensor $\left(r^{2}=0.09 ; p\right.$ value $\left.=0.2\right)$. Thus, we do not expect point SSC time series derived from optical turbidity readings to be biased by flocculation at this site.

\section{Discussion}

In Lower South Bay, the vertical SSC profile changes with semidiurnal oscillations in water velocity and particle settling velocity. Failure to account for changes in the vertical SSC profile in suspended-sediment flux estimates resulted in biased flux estimates, with bias depending on the position of the sensor in the water column (Figs. 3, 4, 5, and 6). If all error is assumed to be random in the $\mathrm{SSC}_{p t}$-to- $\mathrm{SSC}_{x s}$ regression and no correction is applied, changes in the vertical SSC profiles lead to a bias in sediment flux that can alter the sign of the calculated sediment flux. We note that the bias may not be readily apparent in $\mathrm{SSC}_{p t}$ to-SSC $\mathrm{S}_{x s}$ regressions as was the case in WY 2009-2011 (Fig. 4d) and that transformation of regression equations to reduce residual heteroscedasticity does not remove the bias. 
Fig. 8 Cross-section averaged water velocity $\left(U_{x s}\right)$ compared to estimates of the Rouse number (a) and estimates and measurements of settling velocity (b) from the April 2018 deployment. The Rouse number $(R)$ is computed from Eq. 3. Depth-averaged settling velocity $\overline{W_{s}}$ is computed from Eq. 4, and point settling $\left(W_{s}\right)$ at the mid-depth sensor (labeled $W_{s} 7 \mathrm{~m}$ ) is computed from Eq. 17. In situ $W_{s}$ measured at the mid-depth sensor using floc-cam. Point $W_{s}$ estimate from the nearbed and upper sensor is not shown as the time series follow $\overline{W_{s}}$ and $W_{s} 7 \mathrm{~m}$. See Fig. 2 for sensor locations. Note excellent agreement between observed (floc-cam) and estimated $W_{s}$ and semidiurnal variability in $R$ and estimated $W_{s}$ time series. Note that floc-cam $W_{s}$ measurements are scaled by 0.5 ; the slope between floc-cam $W_{s}$ measurements versus $W_{s}$ estimates is expected to be less than 1 since floc-cam $\mathrm{W}_{\mathrm{s}}$ may be biased to larger particles
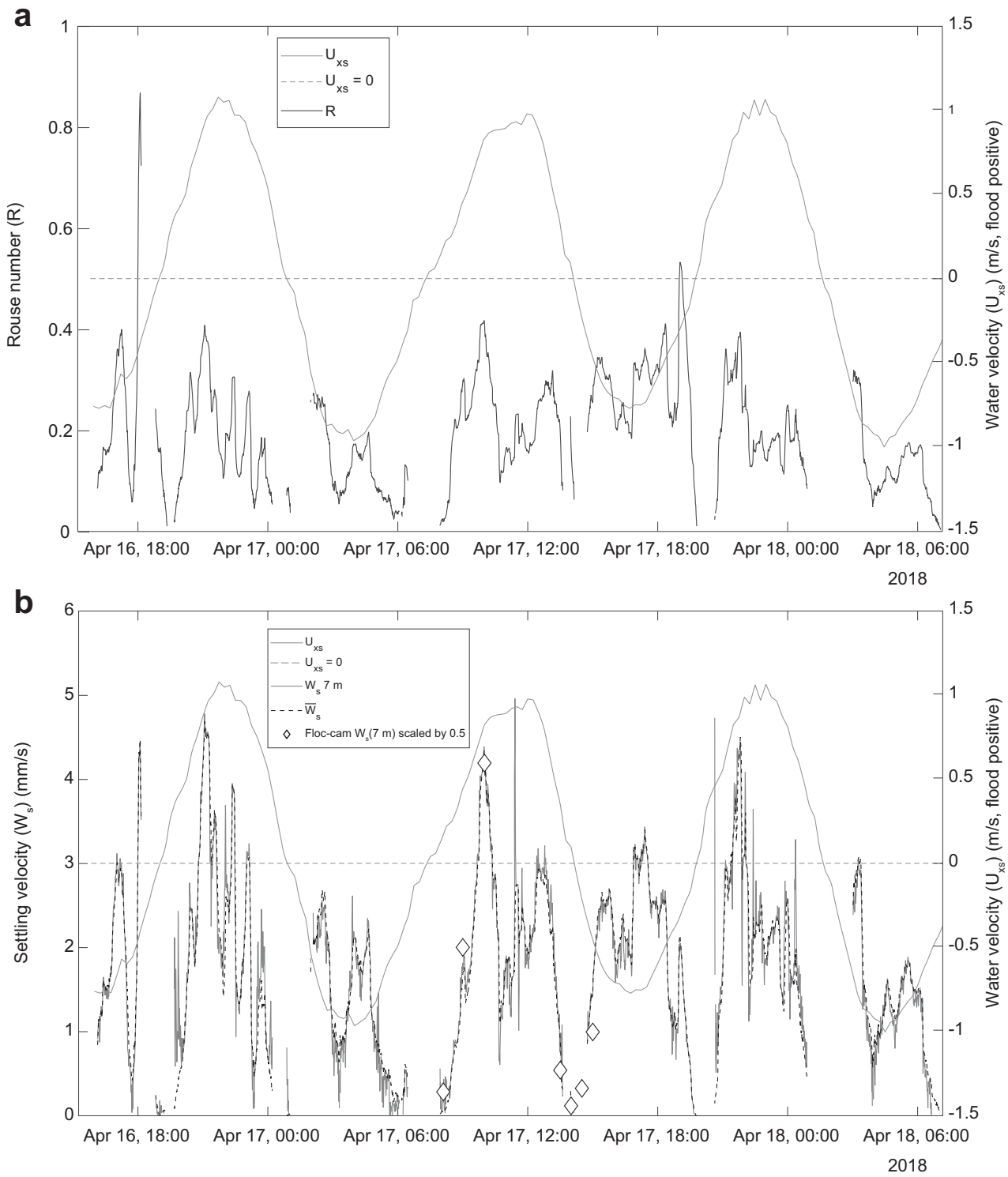

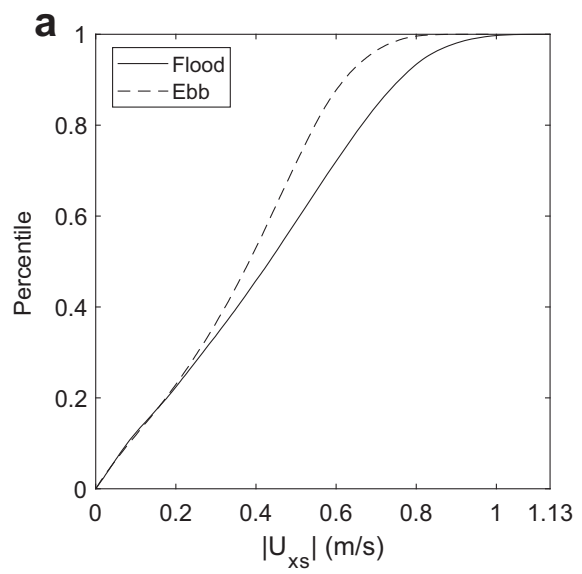

b

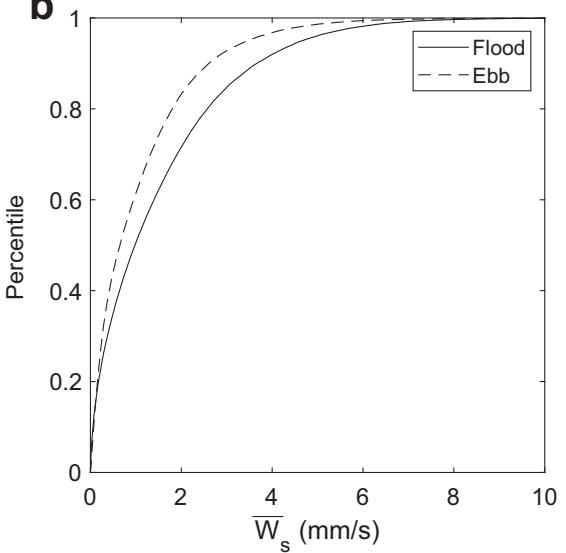

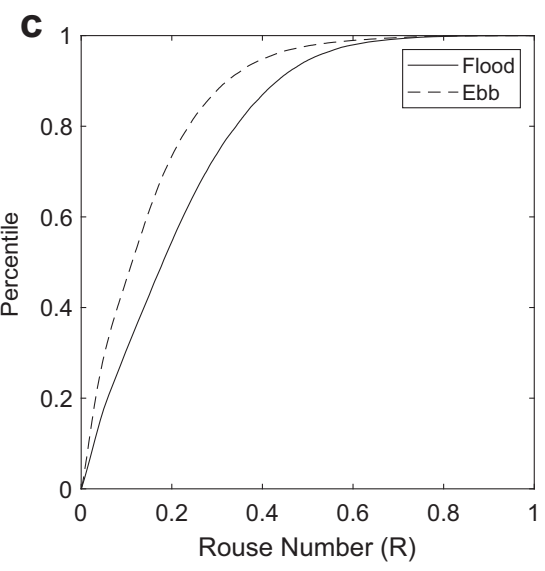

Fig. 9 Empirical cumulative distributions of a cross-section averaged water velocity $\left(U_{x s}\right)$, b depth-averaged settling velocity $\overline{W_{s}}$, and $\mathbf{c}$ Rouse number $(R)$ from combined 2009-2011 and 2013-2016 datasets and separated by flood and ebb tide. Note larger $U_{x s}$ on flood tide would result in smaller $R$ on flood tides compared to ebb tide if $\overline{W_{s}}$ was constant (see Eq. 4); thus, larger $R$ on flood tides is driven by flood-ebb asymmetry in $\overline{W_{s}}$. Datasets (2009-2011 and 2013-2016) exhibit similar differences when analyzed separately 


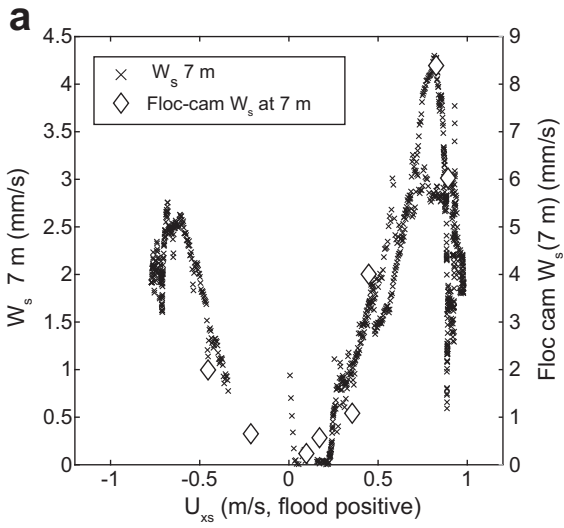

Fig. 10 a Cross-section averaged water velocity $\left(U_{x s}\right)$, point settling $\left(W_{s}\right)$ at mid-depth sensor (labeled $W_{s} 7 \mathrm{~m}$ ), and in situ $W_{s}$ measured at the middepth sensor using floc-cam. b Estimated point settling $\left(W_{s}\right)$ at mid-depth sensor (labeled $W_{s} 7 \mathrm{~m}$ ) and depth-averaged settling velocity $\overline{W_{s}}$ compared to in situ $W_{s}$ measured at the mid-depth sensor using floc-cam. Sampling interval $(d t)$ and number of sensors (near-bed and mid-depth,

Through each tide while water velocity increases from 0 to $\sim$ $0.5 \mathrm{~m} / \mathrm{s}$, depth-averaged settling velocity $\left(\overline{W_{s}}\right)$ increases from $<$ 1 up to $\sim 10 \mathrm{~mm} / \mathrm{s}$ (Figs. 7, 8, 9, and 10). The increase of $R$ with water velocity up to $\sim 0.5 \mathrm{~m} / \mathrm{s}$ and subsequent decrease from $\sim$ $0.5 \mathrm{~m} / \mathrm{s}$ to slack tide (Fig. 7c) indicates changes in the vertical SSC profile, as measured by $R$, are dominated by changes in settling velocity. If settling velocity was fixed, increases in water velocity, proportional to the denominator of $R$ in Eq. 4, would lead to smaller $R$ and decreases in water velocity would lead to increases in $R$. The covariance between water velocity and settling velocity (Figs. 7b, c; 8; and 10) is indicative of turbulence-induced interparticle collision that controls floc aggregation and breakup. Previous field studies of flocculation in San Francisco Estuary indicate that shear stress in the estuary is within the range that allows floc growth and that floc size was best predicted by water speed (Manning and Schoellhamer 2013). The relation between water velocity and particle settling velocity at Dumbarton Bridge (Fig. 10a) is similar to other estuaries, wherein shear-induced interparticle collision and breakup of cohesive sediment control floc-size and settling velocity (e.g., Winterwerp 2002; Winterwerp et al. 2006; Sahin et al. 2017a, 2017b). We note that even in the absence of flocculation of suspended cohesive sediment (e.g., a fixed settling velocity), changes in water velocity (e.g., from tidal influence or discharge events in riverine systems) may result in systematic changes in the vertical SSC profile that when unaccounted for may bias suspended sediment flux estimates. Therefore, results of this work may be applicable to other systems transporting cohesive and non-cohesive sediment.

Larger R on flood compared to ebb tides (Figs. 7a and 9c) explains the change in flux sign from net seaward to net landward at the mid-depth sensor and the reduction in flux magnitude at the near-bed sensor. Larger $\mathrm{R}$ on flood tide indicates sediment tends to be concentrated lower in the water column compared to ebb tides. This causes the uncorrected $\mathrm{SSC}_{p t}$-to-

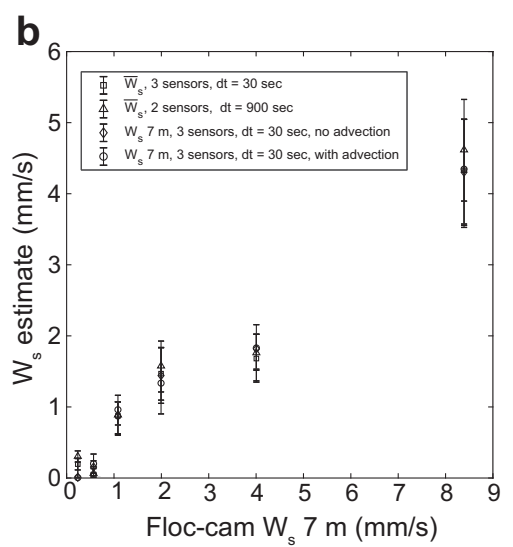

2 sensors; near-bed, lower, and mid-depth 3 sensors) used to compute $W_{s}$ estimate indicated in legend. Outer lines are 2 sigma uncertainty intervals on $W_{s}$ estimates computed from error introduced by conversion of turbidity to point estimates of SSC. The slope between floc-cam $W_{s}$ measurements versus $W_{s}$ estimates is expected to be less than 1 since floc-cam $W_{s}$ may be biased to larger particles

$\mathrm{SSC}_{x s}$ regression at the mid-depth sensor to underestimate flood-directed $\mathrm{SSC}_{x s}$ more then ebb-directed $\mathrm{SSC}_{x s}$. The converse occurs for the near-bed sensor, with more sediment concentrated near the bed on flood tides the uncorrected $\mathrm{SSC}_{p t}$-to$\mathrm{SSC}_{x S}$ regression at the near-bed sensor tends to overestimate flood-directed $\mathrm{SSC}_{x s}$ more than ebb-directed $\mathrm{SSC}_{x s}$.

Despite higher water velocity on flood tides, flood tides exhibit higher $\overline{W_{s}}$ that induces larger $\mathrm{R}$ on flood tides compared to ebb (Fig. 9). Larger $\overline{W_{s}}$ on flood tides with higher water velocity suggests that suspended sediment transported on the flood tide is more cohesive than sediment transported on the ebb tide. The tidal asymmetry in $\overline{W_{s}}$ may be augmented by differences in marine, algal derived, extracellular polymeric substances (EPS) and humic substances. Lee et al. (2017) showed that marine-derived EPS can act to enhance flocculation while terrestrial derived humic substances acted to decrease flocculation. South Bay waters north of Dumbarton Bridge are more marine-influenced and may contain more marine-derived EPS than LSB. LSB, relative to South Bay north of Dumbarton Bridge, has more tidal marsh, watershed inputs, and wastewater treatment plants that could be a source of more terrestrially derived humic substances that reduce flocculation.

Evaluation of Eqs. 3 and 9 can be used to guide optimum placement of sensors for the estimation of $\mathrm{SSC}_{x s}$ in systems where changes in the vertical distribution of suspended sediment are expected to affect suspended sediment flux estimates. We stress, however, that site-specific regressions should be developed to estimate $\mathrm{SSC}_{x s}$ from $\mathrm{SSC}_{p t}$ estimates because of the assumptions in Eqs. 3 and 9 (e.g., a uniform distribution of cross-section suspended sediment cannot be assumed a priori). For estimates of $R$ from Eq. 3, at least two sensors should be located across the range of the largest change in SSC but not near the water surface where assumptions of the Rouse equation are violated (i.e., near-the-bed $\left(\sim \frac{z}{h} \leq 0.1\right)$ and around mid-depth $\left(\frac{z}{h} \sim\right.$ 
$0.5)$ ). Additional sensor placement to better constrain $R$, the slope of Eq. 3, could be prioritized between the near-bed and middepth sensors and between mid-depth and surface. From Eq. 9, $\mathrm{SSC}_{p t}$ estimates from sensors near the bed tend to overestimate $\mathrm{SSC}_{x s}$ when sediment is concentrated near the bed, while $\mathrm{SSC}_{p t}$ estimates from sensors near the surface tend to underestimate $\mathrm{SSC}_{x s}$ when sediment is concentrated near the bed. However, there was no elevation at which $\frac{\mathrm{SSC}_{x s}}{\mathrm{SSC}_{p t}}$ was constant from 0 to $0.5 R$ (not shown). At $\sim \frac{z}{h}=0.4, \frac{\mathrm{SSC}_{x x}}{\mathrm{SSC}_{p t}}$ was nearly constant from 0 to $0.3 R$ (not shown) and may be an ideal placement for a third sensor between the near-bed and mid-depth sensors.

\section{Conclusions}

We demonstrate that unaccounted-for changes in the vertical distribution of suspended sediment lead to biased suspendedsediment-flux estimates at a location in the San Francisco Estuary. Not accounting for systematic changes in the vertical distribution of suspended sediment resulted in biased estimates of suspended-sediment-flux magnitude and sign. Accounting for systematic changes in the vertical distribution of suspended sediment changed sediment flux estimates at a mid-depth sensor from $-319 \mathrm{kt}( \pm 65 \mathrm{kt}$, negative indicating net seaward transport) to $482 \mathrm{kt} \mathrm{(} \pm 140 \mathrm{kt}$, positive indicating net landward transport) for 2009-2011 and from $-388 \mathrm{kt}( \pm 140 \mathrm{kt})$ to $1869 \mathrm{kt}$ ( $\pm 406 \mathrm{kt})$ for 2013-2016. The presented methods do not account for the effect of stratification and reversing flows on the vertical distribution of suspended sediment; however, given the ubiquity of flocculation in tidal systems transporting cohesive sediment, studies aiming to estimate suspended-sediment flux in similar systems may need to determine if the vertical distribution of suspended sediment varies tidally.

Bias in suspended-sediment-flux measurements from unaccounted-for changes in the vertical distribution of suspended sediment varies with position in the water column and increases near the bed and towards the water surface. At the study site, when suspended sediment is concentrated near the bed, cross-section suspended sediment concentration estimates can be overestimated by 2.5 -fold at a sensor $1 \mathrm{~m}$ from the bed and underestimated by 6 -fold at a sensor $1 \mathrm{~m}$ from the water surface. Therefore, flux estimates based on near-bed measurement or surface measurements (e.g., from remote sensing) need to be utilized with caution if the vertical distribution of suspended sediment is expected to change with time. More work is needed to ascertain if changes in the vertical distribution of suspended sediment affect suspended sediment flux estimates in other tidal systems and in systems undergoing unidirectional flow (e.g., rivers).

At the study site the vertical distribution of suspended sediment is controlled primarily by changes in settling velocity mediated by shear-induced floc aggregation and break-up of cohesive sediment. Sediment transport models that assume constant settling velocity may need to consider changes in settling velocity in systems transporting primarily cohesive sediment if additional studies indicate the vertical distribution of suspended sediment is controlled primarily by changes in settling velocity.

List of symbols used in this study

\begin{tabular}{|c|c|c|}
\hline Symbol, units & Definition & $\begin{array}{l}\text { Source } \\
\text { (measure- } \\
\text { ment or } \\
\text { equation) }\end{array}$ \\
\hline $\mathrm{SSC}_{p t}(\mathrm{mg} / \mathrm{l})$ & $\begin{array}{l}\text { Suspended sediment concentration } \\
\text { (SSC) estimated at a point. }\end{array}$ & $\begin{array}{l}\text { Measured } \\
\text { using point } \\
\text { water } \\
\text { sampler }\end{array}$ \\
\hline $\mathrm{SSC}_{x s}(\mathrm{mg} / \mathrm{l})$ & $\begin{array}{l}\text { Cross-section average of } \\
\text { depth-averaged, velocity-weighted } \\
\text { SSC measurements. }\end{array}$ & $\begin{array}{l}\text { Discrete } \\
\text { measure- } \\
\text { ment using } \\
\text { US D-96 } \\
\text { sampler }\end{array}$ \\
\hline$W_{s}(\mathrm{~m} / \mathrm{s})$ & Particle settling velocity & $\begin{array}{l}\text { Measured and } \\
\text { estimated } \\
\text { from } \\
\text { equations } \\
\text { (see below) }\end{array}$ \\
\hline$T_{b}(\mathrm{FNU})$ & Turbidity at a point & $\begin{array}{l}\text { Continuous } \\
\text { measure- } \\
\text { ment using } \\
\text { optical } \\
\text { backscatter- } \\
\text { ing sensor }\end{array}$ \\
\hline$U_{i}(\mathrm{~m} / \mathrm{s})$ & $\begin{array}{l}\text { Water velocity at a point or average of } \\
\text { profile measurement. }\end{array}$ & $\begin{array}{l}\text { Continuous } \\
\text { measure- } \\
\text { ment using } \\
\text { acoustic } \\
\text { Doppler } \\
\text { current } \\
\text { profiler }\end{array}$ \\
\hline$p$ (dbar) & Stage, depth of water above sensor & $\begin{array}{l}\text { Continuous } \\
\text { measure- } \\
\text { ment using } \\
\text { acoustic } \\
\text { Doppler } \\
\text { current } \\
\text { profiler }\end{array}$ \\
\hline$U_{x s}(\mathrm{~m} / \mathrm{s})$ & Water velocity, cross-section average & $\begin{array}{l}\text { Discrete } \\
\text { measure- } \\
\text { ment using } \\
\text { acoustic } \\
\text { Doppler } \\
\text { current } \\
\text { profiler }\end{array}$ \\
\hline$A_{x s}\left(\mathrm{~m}^{2}\right)$ & $\begin{array}{l}\text { Area of cross-section below water } \\
\text { surface }\end{array}$ & $\begin{array}{l}\text { Discrete } \\
\text { measure- } \\
\text { ment using } \\
\text { acoustic } \\
\text { Doppler } \\
\text { current } \\
\text { profiler }\end{array}$ \\
\hline$Q_{x s}\left(\mathrm{~m}^{3} / \mathrm{s}\right)$ & Discharge, cross-section average & Eq. 1 \\
\hline
\end{tabular}




\begin{tabular}{|c|c|c|}
\hline$Q_{s}(\mathrm{kt} / \mathrm{s})$ & $\begin{array}{l}\text { Suspended sediment flux through } \\
\text { cross-section }\end{array}$ & Eq. 2 \\
\hline $\mathrm{SSC}_{p t}^{\prime}(\mathrm{mg} / \mathrm{l})$ & SSC at a point, theoretically derived & Eq. 3 \\
\hline $\begin{array}{r}\operatorname{SSC}_{p t}^{\prime}(z) \\
(\mathrm{mg} / \mathrm{l})\end{array}$ & $\mathrm{SSC}_{p t}^{\prime}$ at elevation $z$ above the bed & Eq. 3 \\
\hline $\begin{array}{r}\operatorname{SSC}_{p t}^{\prime}(a) \\
(\mathrm{mg} / \mathrm{l})\end{array}$ & $\begin{array}{l}\mathrm{SSC}_{p t}^{\prime} \text { at reference elevation } a \text { above } \\
\text { the bed }\end{array}$ & Eq. 3 \\
\hline$z(\mathrm{~m})$ & Elevation above the bed & Eq. 3 \\
\hline$a(\mathrm{~m})$ & Reference elevation above the bed & Eq. 3 \\
\hline$h(\mathrm{~m})$ & Elevation of water surface above bed & Eq. 3 \\
\hline$R$ & Rouse number & Eq. 3 \\
\hline$\overline{W_{s}}(\mathrm{~m} / \mathrm{s})$ & $\begin{array}{l}\text { Depth-averaged particle settling } \\
\text { velocity }\end{array}$ & Eq. 3 \\
\hline$\beta$ & The inverse turbulent Schmidt number & Eq. 3 \\
\hline$\kappa$ & Von Kármán constant & Eq. 3 \\
\hline$u_{*}(\mathrm{~m} / \mathrm{s})$ & Shear velocity & Eq. 4 \\
\hline$\tau_{b}\left(\mathrm{~N} / \mathrm{m}^{2}\right)$ & Bottom shear stress & Eq. 5 \\
\hline$\rho\left(\mathrm{kg} / \mathrm{m}^{3}\right)$ & Density of fluid & Eq. 5 \\
\hline$C_{d}$ & Drag coefficient & Eq. 5 \\
\hline$u(\mathrm{~m} / \mathrm{s})$ & Along-channel water velocity & Eq. 5 \\
\hline$U^{\prime}(z)(\mathrm{m} / \mathrm{s})$ & Fluid velocity at elevation $z$ & Eq. 6 \\
\hline$z_{o}(\mathrm{~m})$ & Roughness length & Eq. 6 \\
\hline $\mathrm{SSC}_{x S}^{\prime}(\mathrm{mg} / \mathrm{l})$ & $\mathrm{SSC}_{x s}$, theoretically derived & Eq. 7 \\
\hline$\alpha_{\operatorname{SSC}_{p t}(z)}$ & $\begin{array}{l}\text { The theoretical ratio of } \frac{\mathrm{SSC}_{x s}^{\prime} \mathrm{SSC}_{p t}^{\prime}}{\text { at }} \\
\text { elevation } z\end{array}$ & Eq. 9 \\
\hline$\widehat{\mathrm{SSC}^{\prime}}$ & $\begin{array}{l}\mathrm{SSC}_{p t}^{\prime} \text { averaged over depth range, } \\
\text { theoretically derived }\end{array}$ & Eq. 10 \\
\hline$\alpha^{\prime} \widehat{\mathrm{SCC}}$ & The theoretical ratio of $S^{S C_{x s}^{\prime}}$ & Eq. 10 \\
\hline$\alpha_{\mathrm{SSC}_{p t}(z)}$ & $\begin{array}{l}\text { The ratio of } \frac{\mathrm{SSC}_{x s}}{T_{b}} \text {, an empirical } \\
\text { measurement-based estimate of } \alpha \\
\quad \text { ' } \mathrm{SSC}_{p t}(z)\end{array}$ & Eqs. 14 \\
\hline$t$ & Time & Eq. 16 \\
\hline$W_{s}(z)(\mathrm{m} / \mathrm{s})$ & $\begin{array}{l}\text { Settling velocity estimated at a point } z \\
\text { meters from the bed. }\end{array}$ & Eqs. 17 \\
\hline$K\left(\mathrm{~m}^{2} / \mathrm{s}\right)$ & Eddy diffusivity & Eq. 17 \\
\hline$x(\mathrm{~m})$ & $\begin{array}{l}\text { Along-channel (longitudinal) coordi- } \\
\text { nate }\end{array}$ & Eq. 17 \\
\hline
\end{tabular}

Funding Information The Regional Monitoring Program for Water Quality in San Francisco Bay and a San Francisco Bay Water Board enforcement action provided funding for data collection.

\section{References}

Barnard, P.L., A.C. Foxgrover, E.P. Elias, L.H. Erikson, J.R. Hein, M. McGann, K. Mizell, R.J. Rosenbauer, P.W. Swarzenski, R.K. Takesue, and F.L. Wong. 2013. Integration of bed characteristics, geochemical tracers, current measurements, and numerical modeling for assessing the provenance of beach sand in the San Francisco Bay Coastal System. Marine Geology 345: 181-206.

Brand, A., Lacy, J.R., Hsu, K., Hoover, D., Gladding, S. and Stacey, M.T., 2010. Wind-enhanced resuspension in the shallow waters of South San Francisco Bay: Mechanisms and potential implications for cohesive sediment transport. Journal of Geophysical Research: Oceans, 115(C11).

Bricker, J.D., S. Inagaki, and S.G. Monismith. 2005. Bed drag coefficient variability under wind waves in a tidal estuary. Journal of Hydraulic Engineering 131 (6): 497-508.

Buchanan, P.A., Downing-Kunz, M.A., Schoellhamer, D.H., and Livsey, D.N., 2018. Continuous water-quality and suspended-sediment transport monitoring in the San Francisco Bay, California, water years 2014-15, U.S. Geological Survey Fact Sheet 2018-3013. Accessible online at https://doi.org/10.3133/fs20183013.

Caffrey, J.M. 1995. Spatial and seasonal patterns in sediment nitrogen remineralization and ammonium concentrations in San Francisco Bay, California. Estuaries 18 (1): 219-233.

Cheng, R.T., C.H. Ling, J.W. Gartner, and P.F. Wang. 1999. Estimates of bottom roughness length and bottom shear stress in South San Francisco Bay, California. Journal of Geophysical Research: Oceans 104 (C4): 7715-7728.

Conomos, T.J., R.E. Smith, and J.W. Gartner. 1985. Environmental setting of San Francisco Bay. In Temporal dynamics of an estuary: San Francisco Bay, 1-12. Dordrecht: Springer.

Downing, J. 2006. Twenty-five years with OBS sensors: The good, the bad, and the ugly. Continental Shelf Research 26 (17-18): 22992318.

Downing-Kunz, M.A., and D.H. Schoellhamer. 2013. Seasonal variations in suspended-sediment dynamics in the tidal reach of an estuarine tributary. Marine Geology 345: 314-326.

Edwards, T.K. and Glysson, G.D., 1999. Field methods for measurement of fluvial sediment: US Geological Survey Techniques of WaterResources Investigations, book 3, chap.

Eisma, D. 1986. Flocculation and de-flocculation of suspended matter in estuaries. Netherlands Journal of Sea Research 20 (2-3): 183-199.

Elias, E., Hansen, J., and Erikson, L.H. 2013. San Francisco Bay Basic Tide Model, http://walrus.wr.usgs.gov/coastal_processes/ sfbaycoastalsys/SFBay_model/, https://doi.org/10.5066/ F7DN4330.

García, M.H. 2008. Sedimentation engineering: Processes, measurements, modeling, and practice (ASCE manuals and reports on engineering practice). Reston: American Society of Civil Engineers/ ASCE.

Gartner, J.W., R.T. Cheng, P.F. Wang, and K. Richter. 2001. Laboratory and field evaluations of the LISST-100 instrument for suspended particle size determinations. Marine Geology 175 (1-4): 199-219.

Hager, S.W., and L.E. Schemel. 1996. Dissolved inorganic nitrogen, phosphorus, and silicon in South San Francisco Bay. I. Major factors affecting distributions. In San Francisco Bay: The ecosystem, Pacific division, ed. J.T. Hollibaugh, 189-215. San Francisco: American Association for the Advancement of Science.

Helsel, D.R. and Hirsch, R.M., 2002. Statistical methods in wter resources. Techniques of water resources investigations, Book 4, chapter A3. U.S. Geological Survey. https://doi.org/10.3133/ twri04A3.

Jaffe, B., and A.C. Foxgrover. 2006. Sediment deposition and erosion in South San Francisco Bay, California from 1956 to 2005, 20. Reston: US Geological Survey.

Lee, B.J., J. Hur, and E.A. Toorman. 2017. Seasonal variation in flocculation potential of river water: Roles of the organic matter pool. Water. 9 (5): 335.

Levesque VA, Oberg KA., 2012. Computing discharge using the index velocity method: US Geological Survey Techniques and Methods 3-A23, 148 p. Also available at http://pubs.usgs.gov/tm/3a23/.2012.

Love, A.H., B.K. Esser, and J.R. Hunt. 2003. Reconstructing contaminant deposition in a San Francisco Bay marine, California. Journal of Environmental Engineering 129 (7): 659-666.

Lucas, L.V., J.R. Koseff, S.G. Monismith, and J.K. Thompson. 2009. Shallow water processes govern system-wide phytoplankton 
dynamics: A modeling study. Journal of Marine Systems 75: 70-86. https://doi.org/10.1016/j.marsys.2008.07.011.

Manning, A.J. 2004a. Observations of the properties of flocculated cohesive sediment in three western European estuaries. Journal of Coastal Research SI41: 70-81.

Manning, A.J. 2004b. The observed effects of turbulence on estuarine flocculation. Journal of Coastal Research SI41: 90-104.

Manning, A.J., and K.R. Dyer. 2002. The use of optics for the in-situ determination of flocculated mud characteristics. Journal of Optics A: Pure and Applied Optics 4: S71-S81.

Manning, A.J., and K.R. Dyer. 2007. Mass settling flux of fine sediments in Northern European estuaries: Measurements and predictions. Marine Geology 245: 107-122. https://doi.org/10.1016/j.margeo. 2007.07.005.

Manning, A.J., and D.H. Schoellhamer. 2013. Factors controlling floc settling velocity along a longitudinal estuarine transect. Marine Geology 1 (345): 266-280.

Manning, A.J., Friend, P.L., Prowse, N. and Amos, C.L. (2007). Preliminary findings from a study of Medway Estuary (UK) natural mud floc properties using a laboratory mini-flume and the LabSFLOC system. Continental Shelf Research, doi:https://doi. org/10.1016/j.csr.2006.04.011.

Manning, A.J., Baugh, J.V., Spearman, J. and Whitehouse, R.J.S., 2010. Flocculation settling characteristics of mud: Sand mixtures. Ocean Dynamics, doi: https://doi.org/10.1007/s10236-009-0251-0.

Manning, A.J., Baugh, J.V., Soulsby, R.L., Spearman, J.R. and Whitehouse, R.J.S., 2011. Cohesive sediment flocculation and the application to settling flux modelling. In: Silvia Susana Ginsberg (Ed.), Sediment transport, Publisher: InTech (Vienna), Chapter 5, pp. 91-116, DOI: https://doi.org/10.5772/16055.

Manning, A.J., Whitehouse, R.J.S. and Uncles, R.J.. 2017. Suspended particulate matter: The measurements of flocs. In: R.J. Uncles and S. Mitchell (Eds), ECSA practical handbooks on survey and analysis methods: Estuarine and coastal hydrography and sedimentology, Chapter 8, pp. 211-260, Pub. Cambridge University Press, DOI: https://doi.org/10.1017/9781139644426, ISBN 978-1-107-04098-4.

Markussen, T.N., and T.J. Andersen. 2013. A simple method for calculating in situ floc settling velocities based on effective density functions. Marine Geology 344: 10-18.

Markussen, T.N., and T.J. Andersen. 2014. Flocculation and floc breakup related to tidally induced turbulent shear in a low-turbidity, microtidal estuary. Journal of Sea Research 89: 1-11.

McGann, M., L. Erikson, E. Wan, C. Powell, and R.F. Maddocks. 2013. Distribution of biologic, anthropogenic, and volcanic constituents as a proxy for sediment transport in the San Francisco Bay Coastal System. Marine Geology 345: 113-142.

McKee, L.J., M. Lewicki, D.H. Schoellhamer, and N.K. Ganju. 2013. Comparison of sediment supply to San Francisco Bay from watersheds draining the Bay Area and the Central Valley of California. Marine Geology 345: 47-62.

Mikeš, D., and A.J. Manning. 2010. An assessment of flocculation kinetics of cohesive sediments from the Seine and Gironde estuaries, France, through laboratory and field studies. Journal of Waterway, Port, Coastal, and Ocean Engineering (ASCE) 136 (6): 306-318. https://doi.org/10.1061/(ASCE)WW.1943-5460.0000053.

Ruhl, C.A., and M.R. Simpson. 2005. Computation of discharge using the index-velocity method in tidally affected areas, 1-41. Denver: US Department of the Interior, US Geological Survey.

Rustomji, P., and S.N. Wilkinson. 2008. Applying bootstrap resampling to quantify uncertainty in fluvial suspended sediment loads estimated using rating curves. Water Resources Research 44 (9).

Sahin, C., H.A.A. Guner, M. Ozturk, and A. Sheremet. 2017a. Floc size variability under strong turbulence: Observations and artificial neural network modeling. Applied Ocean research 68: 130-141.

Sahin, C., R. Verney, A. Sheremet, and G. Voulgaris. 2017b. Acoustic backscatter by suspended cohesive sediments: Field observations, Seine Estuary, France. Continental Shelf Research 134: 39-51.

Schraga, T.S. \& Cloern, J.E., 2017, Water quality measurements in San Francisco Bay by the U.S. Geological Survey, 1969-2015. Scientific Data 4:170098 doi:https://doi.org/10.1038/sdata.2017.98.

Schraga, T.S., Nejad, E.S., Martin, C.A., and Cloern, J.E., 2018, USGS measurements of water quality in San Francisco Bay (CA), beginning in 2016 (ver. 2.0, June 2018): U.S. Geological Survey data release, https://doi.org/10.5066/F7D21WGF.

Shellenbarger, G.G., S.A. Wright, and D.H. Schoellhamer. 2013. A sediment budget for the southern reach in San Francisco Bay, CA: Implications for habitat restoration. Marine Geology 345: 281-293.

Soulsby, R.L., A.J. Manning, J. Spearman, and R.J.S. Whitehouse. 2013. Settling velocity and mass settling flux of flocculated estuarine sediments. Marine Geology. https://doi.org/10.1016/j.margeo.2013.04. 006.

Webster, M.D., Pope, G.L., Friebel, M.F., Freeman, L.A., Brockner, S.J., 2005. Water resources data, California, water year 2004: Volume 2, Pacific slope basins from Arroyo Grande to Oregon state line except Central Valley. (USGS Water-Data Report CA-04-2). (445 pp.).

Winterwerp, J.C. 2002. On the flocculation and settling velocity of estuarine mud. Continental Shelf Research 22 (9): 1339-1360.

Winterwerp, J.C., A.J. Manning, C. Martens, T. de Mulder, and J. Vanlede. 2006. A heuristic formula for turbulence-induced flocculation of cohesive sediment. Estuarine, Coastal and Shelf Science 68: 195-207.

Zhang, N., C.E.L. Thompson, I.H. Townend, K.E. Rankin, D.M. Paterson, and A.J. Manning. 2018. Nondestructive 3D imaging and quantification of hydrated biofilm-sediment aggregates using $\mathrm{X}$-ray microcomputed tomography. Environmental Science \& Technology 52 (22): 13306-13313. https://doi.org/10.1021/acs.est. 8b03997. 